\title{
Demonstration Assessment of Light-Emitting Diode (LED) Roadway Lighting on Residential and Commercial Streets
}

\section{Host Site: Palo Alto, California}

Final Report prepared in support of the U.S. DOE Solid-State Lighting

Technology Demonstration GATEWAY Program

\section{Study Participants:}

Pacific Northwest National Laboratory

U.S. Department of Energy

City of Palo Alto

June 2010

Prepared for the U.S. Department of Energy by

Pacific Northwest National Laboratory 


\section{DISCLAIMER}

This report was prepared as an account of work sponsored by an agency of the United States Government. Neither the United States Government nor any agency thereof, nor Battelle Memorial Institute, nor any of their employees, makes any warranty, express or implied, or assumes any legal liability or responsibility for the accuracy, completeness, or usefulness of any information, apparatus, product, or process disclosed, or represents that its use would not infringe privately owned rights. Reference herein to any specific commercial product, process, or service by trade name, trademark, manufacturer, or otherwise does not necessarily constitute or imply its endorsement, recommendation, or favoring by the United States Government or any agency thereof, or Battelle Memorial Institute. The views and opinions of authors expressed herein do not necessarily state or reflect those of the United States Government or any agency thereof.

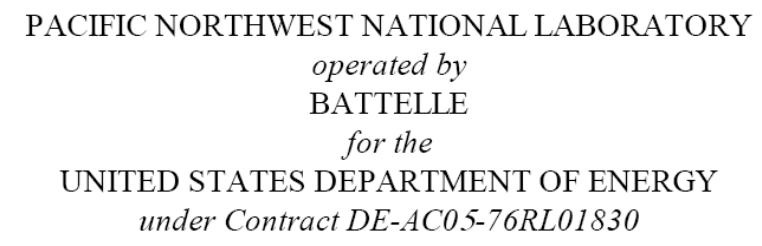

Printed in the United States of America

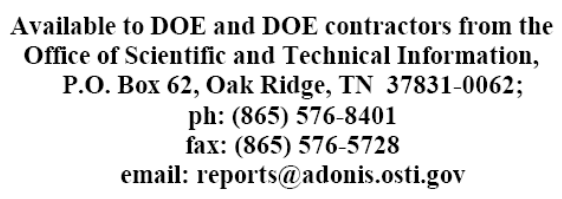

Available to the public from the National Technical Information Service,

U.S. Department of Commerce, 5285 Port Royal Rd., Springfield, VA 22161

ph: (800) 553-6847

fax: (703) 605-6900

email: orders@ntis.fedworld.gov

online ordering: http://www.ntis.gov/ordering.htm

Electronic copies of the report are also available from the DOE Solid State Lighting website at

http://wwwl.eere.energy.gov/buildings/ssl/gatewaydemos.html.

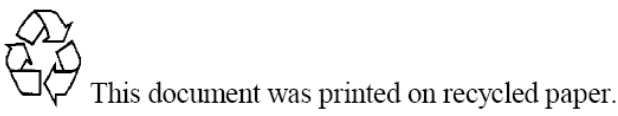

$(9 / 2003)$ 


\section{Demonstration Assessment of Light-Emitting Diode (LED) Roadway Lighting on Residential and Commercial Streets in Palo Alto, California}

Final Report prepared in support of the U.S. DOE Solid-State Lighting

Technology Demonstration GATEWAY Program

Study Participants:

Pacific Northwest National Laboratory

U.S. Department of Energy

City of Palo Alto

MA Myer

BR Kinzey

C Tam

June 2010

Prepared for

the U.S. Department of Energy

under Contract DE-AC05-76RL01830

Pacific Northwest National Laboratory

Richland, Washington 99352 


\section{Preface}

This document is a report of observations and results obtained from a lighting demonstration project conducted under the U.S. Department of Energy (DOE) GATEWAY Demonstration Program. The program supports demonstrations of high-performance solid-state lighting (SSL) products in order to develop empirical data and experience with in-the-field applications of this advanced lighting technology. The DOE GATEWAY Demonstration Program focuses on providing a source of independent, third-party data for use in decision-making by lighting users and professionals; this data should be considered in combination with other information relevant to the particular site and application under examination. Each GATEWAY demonstration compares one SSL product against the incumbent technology used in that location. Depending on available information and circumstances, the SSL product may also be compared to alternative lighting technologies. Although products demonstrated in the GATEWAY program have been prescreened and tested to verify their actual performance, DOE does not endorse any commercial product or in any way guarantee that users will achieve the same results through use of these products. 


\section{Summary}

This report documents the findings of a demonstration project conducted in the city of Palo Alto, California, to evaluate the feasibility of replacing high-pressure sodium (HPS) streetlights with a variety of advanced technologies. The technologies evaluated include light-emitting diode (LED) and induction luminaires as well as remote streetlight monitoring and dimming technology. All of these were evaluated in terms of their lighting and energy performance and economics relative to the existing HPS streetlighting system.

One vendor each for LED and induction streetlight luminaires was selected, consisting of BetaLED and Deco Lighting, respectively, while Echelon's system was used for the remote streetlight monitoring demonstration on a commercial street in the center of Palo Alto.

A total of seven LED and three induction streetlight luminaires were installed on two residential streets in Palo Alto, replacing 70-W (nominal) HPS luminaires. Illuminance measurements were taken for the test sites both before and after the installation of the LED and induction luminaires. Power measurements were taken at each LED and induction streetlight pole as well as at neighboring HPS streetlight poles.

To test the remote monitoring system, two LED and two induction luminaires were installed near the City Hall building in downtown Palo Alto. These luminaires were equipped with Echelon communication hardware that can be remotely controlled through a desktop or laptop personal computer. These luminaires were programmed to turn on and off on a schedule similar to that of the streetlight luminaires controlled by a photocell but then were dimmed by $25 \%$ of full power for 5 hours each evening.

Measurement results from the demonstration project show that LED luminaires produce more uniform light output than that of HPS and induction luminaires. LED luminaires also have much better cutoff on the curbside of the streetlight luminaire, resulting in significantly reduced light trespass onto residential properties. Of the three systems (induction, HPS, and LED), the LED used the least energy (44\% reduction compared to the baseline HPS). Factors contributing to this result include source and power supply efficiencies and inefficiencies of conventional cobra head types of fixtures.

Community feedback was obtained during this study but was collected through multiple anecdotal means. The community feedback was designed to seek input on the options available to the city to reduce the energy usage of its street lighting system. Overall results from respondents show a marked preference for LED lights over induction lights. Nevertheless, two common concerns related to LED lights were excessive glare and the perceived blue/cold color of the LED light output. These issues will have to be resolved prior to a mass rollout of LED streetlights for Palo Alto. The LED luminaires tested in the demonstration have a correlated color temperature (CCT) of $6000 \mathrm{~K}$; by comparison, the CCT for the induction and HPS streetlights were $5000 \mathrm{~K}$ and $2100 \mathrm{~K}$, respectively. Lower-CCT LED luminaires, which generally exhibit reduced efficacy, were not investigated in this study.

Because Palo Alto is a municipal utility that operates its own streetlights at cost, avoided costs were used to evaluate the economics. The $\$ 0.08 / \mathrm{kWh}$ avoided cost used accounted for marginal energy and transmission costs but excluded typical distribution charges. In addition to the energy charge, a 
greenhouse gas carbon adder was used in the evaluation, per the city's guidance. The city uses a low-cost cobra head fixture with an associated first cost of $\$ 78$. The combination of low energy cost and fixture cost presents a difficult hurdle for proposed alternatives that involve any incremental cost. At an average annual baseline electricity usage cost of $\$ 32$, the value of the $44 \%$ energy savings from the LED option translates to only about $\$ 14$ per year. Maintenance savings was estimated to add about $\$ 17$ per year, for a total return of about $\$ 31$ per year from this potential investment.

Combined with the low $\$ 78$ price of the cobra head, none of the three options investigated for saving energy (i.e., replacing HPS with either LED or induction, or employing a dimming control system) could meet both the performance and economic criteria required for widespread implementation in Palo Alto. For Palo Alto, the performance criterion was matching the illumination of the existing HPS installation system, whereas the economic criterion consisted of achieving a positive net present value.

The simple payback for retrofitting a 70-W (nominal) HPS with an LED luminaire offering illuminance comparable to that of the HPS was estimated to be around 12 years, improving to about 10 years in a new construction scenario. This option showed a negative net present value (NPV) for the retrofit and slightly positive NPV for the new construction scenarios. A smaller LED system configuration offered better payback and positive net present values across both scenarios but did not provide sufficient illumination to be considered an adequate replacement.

The remote monitoring/dimming system performed as anticipated. However, based on the current cost of the technology, it was similarly uneconomical to deploy in this location. For the scenario of retrofitting a 150-W HPS with an LED luminaire, deploying the remote monitoring system with a daily schedule of dimming the luminaire by $25 \%$ had a net negative present value and further increased the simple payback of the overall installation by more than 3 years.

Ultimately, although energy savings was achieved through all of the tested alternatives, commoditygrade pricing for the incumbent HPS and low cost of electricity in this location continue to pose difficult obstacles for justifying the investment based solely on the current valuation of benefits. Expanded recognition (or monetization) of benefits, such as the broad spectrum output that increases color recognition or new control capabilities that facilitate emergency response, will likely be necessary to justify upgrades to the lighting system in locations where such economic conditions apply. 


\section{Acronyms and Abbreviations}

\begin{tabular}{ll} 
A & ampere(s) \\
BUG & backlight, uplight, and glare \\
CEAP & Community Environmental Action Partnership \\
$\mathrm{CO}_{2}$ & carbon dioxide \\
Council & City Council of Palo Alto, California \\
CPP & Climate Protection Plan \\
CRI & color rendering index \\
CV & coefficient of variation \\
DOE & U.S. Department of Energy \\
fc & footcandle(s) \\
GHG & greenhouse gas \\
GWh & gigawatt-hour(s) \\
HID & high-intensity discharge \\
HPS & high-pressure sodium \\
HPV & net present value \\
IESNA & Illuminating Engineering Society of North America \\
kWh & kilowatt-hour(s) \\
LCS & luminaire classification system \\
LED & light-emitting diode \\
lm/W & lumen(s) per watt \\
mA & milliampere(s) \\
NVLAP & National Voluntary Laboratory Accreditation Program \\
PNNL & Pacific Northwest National Laboratory \\
Std. Dev. & standard deviation \\
W & watt(s) \\
& \\
\hline &
\end{tabular}




\section{Contents}

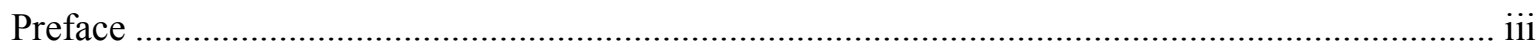

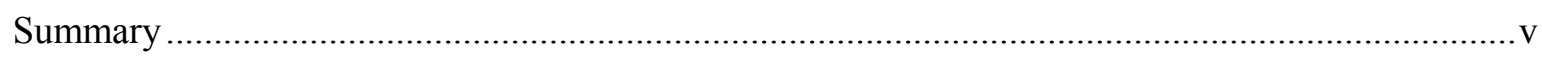

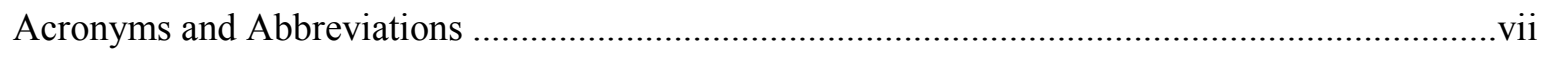

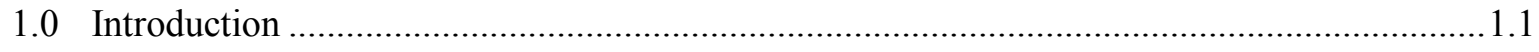

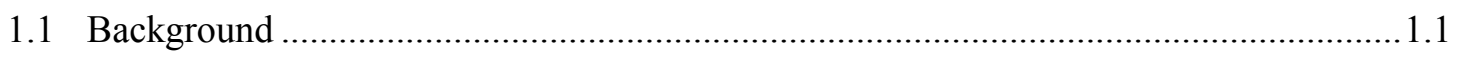

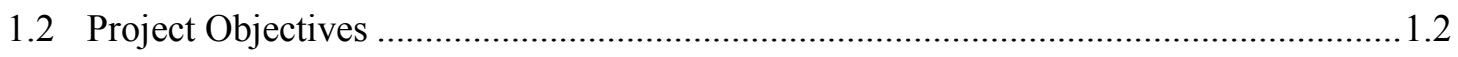

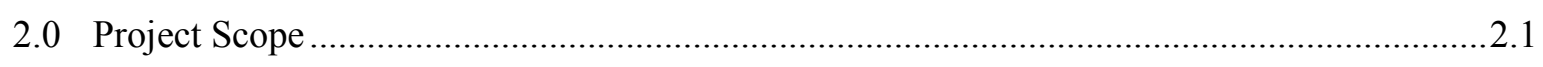

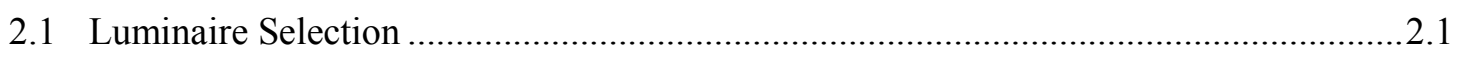

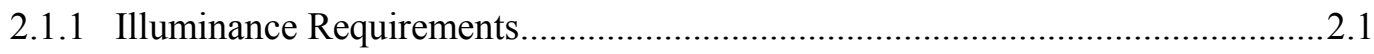

2.1.2 Existing High-Pressure Sodium Luminaires ...............................................2.2

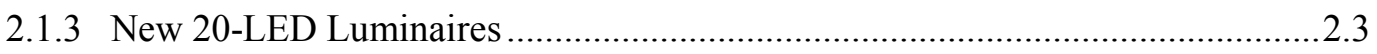

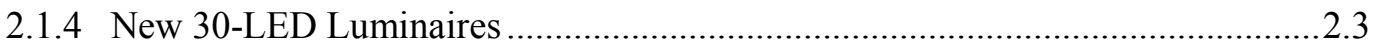

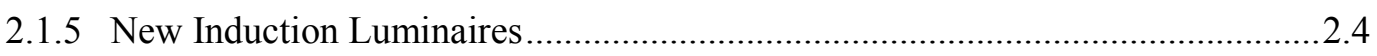

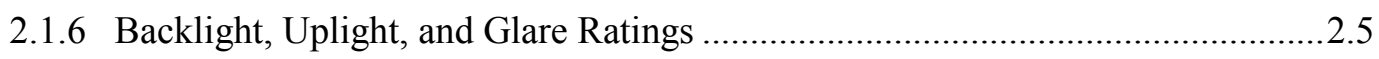

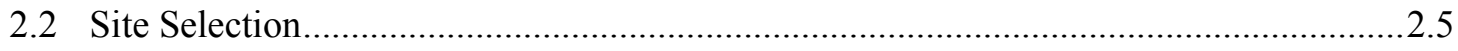

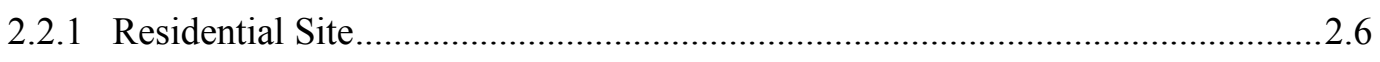

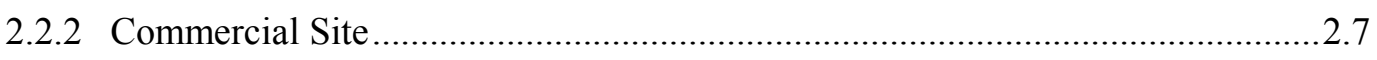

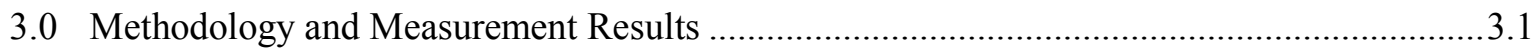

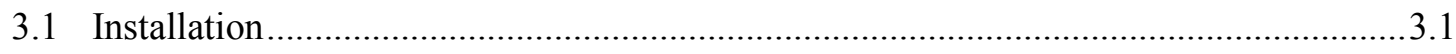

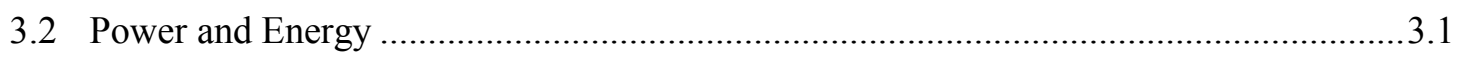

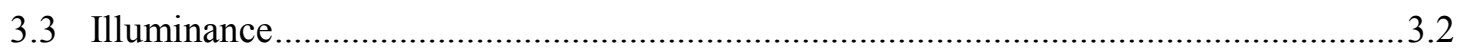

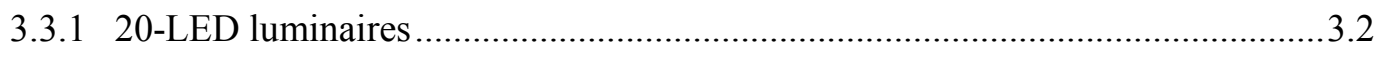

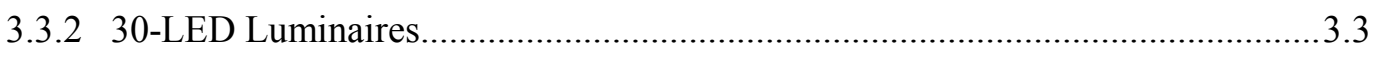

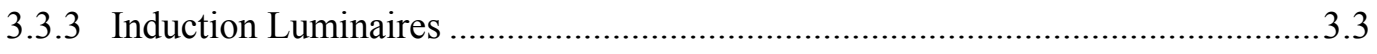

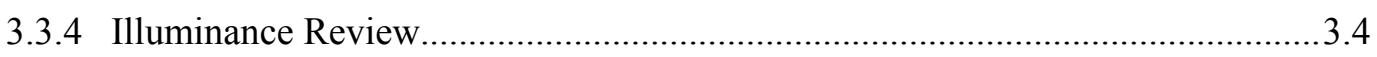

4.0 Commercial Site and Monitoring System Evaluation ..................................................... 4.1

4.1 Evaluation of Commercial Streetlight with HPS Luminaires ...................................... 4.1

4.2 Evaluation of Commercial Streetlight with LED Luminaires ......................................... 4.1

4.3 Evaluation of Commercial Streetlight with Induction Luminaires ..................................2

4.4 Summary of Evaluation of Commercial Streetlight Pilot............................................. 4.2

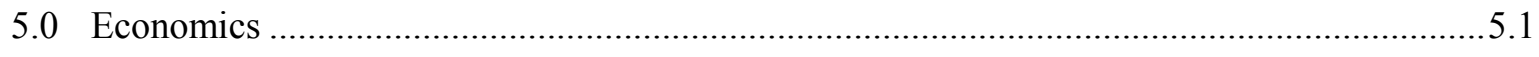

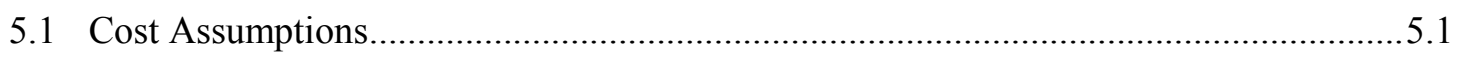

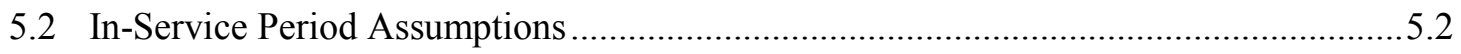

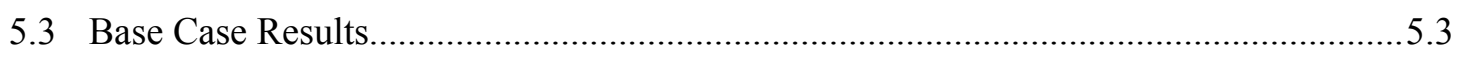

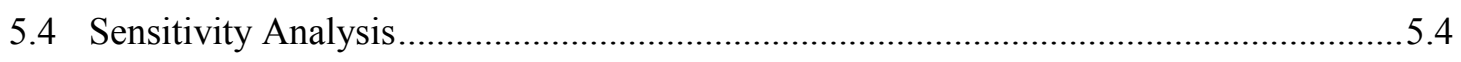

5.4.1 Sensitivity Analysis on the In-Service Period of LEDs ....................................5.4 
5.4.2 Sensitivity Analysis on the Luminaire Cost of LEDs ........................................5.4

5.4.3 Sensitivity Analysis on the Initial Efficacy of LEDs ...........................................5.5

5.4.4 Sensitivity Analysis on the Maintenance Cost of LEDs ......................................5.5

5.5 Economics for Replacing Different HPS Wattage with LED Luminaires .....................5.7

5.6 Economics for Remote Monitoring and Dimming Control............................................. 5.8

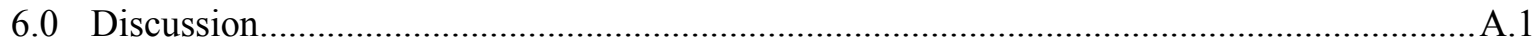

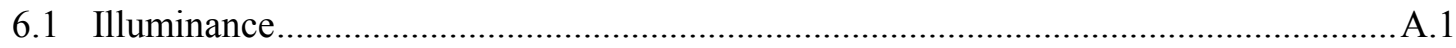

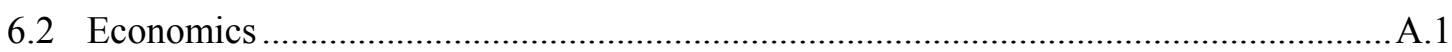

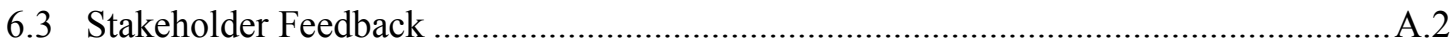

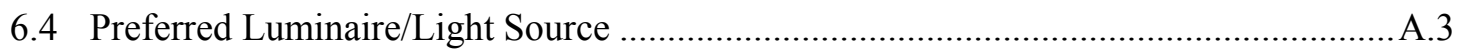

Appendix A Luminaire Photometric Testing Results ............................................................... A.3

Appendix B Considerations Regarding Photometry and .IES Files .......................................... B.1

Appendix C LED/Induction Streetlight Pilot Project Notification Letter to Residents ................. C.2 


\section{Figures}

2.1 High-Pressure Sodium Luminaire Distribution............................................................... 2.2

2.2 20-LED Luminaire Distribution................................................................................. 2.3

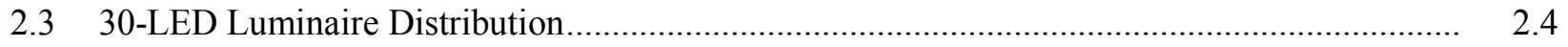

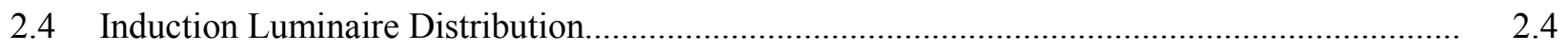

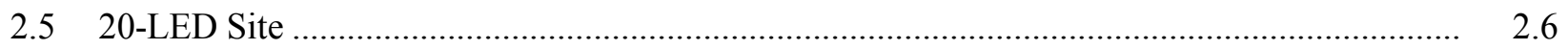

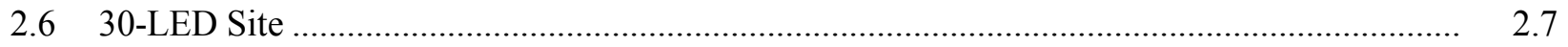

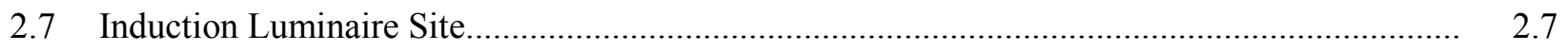

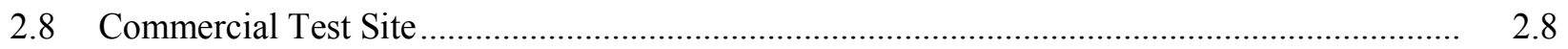

5.1 Sensitivity Analysis on the Net Present Value of 20-LED Luminaires

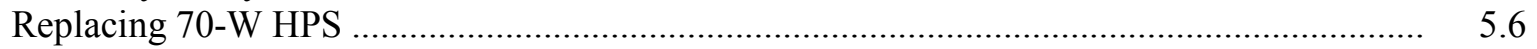

5.2 Sensitivity Analysis on the Net Present Value of 30-LED Luminaires

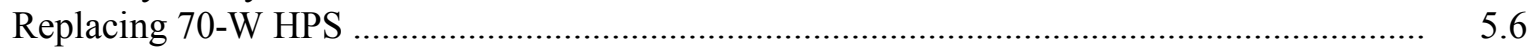

\section{Tables}

2.1. Backlight, Uplight, and Glare Ratings ....................................................................... 2.5

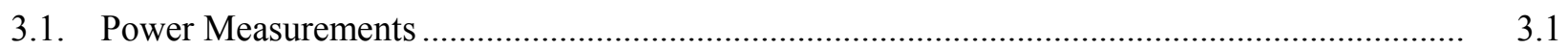

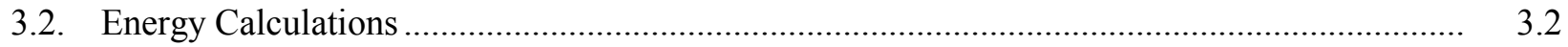

3.3. Summary of Measured Illuminance on Colorado Avenue (poles 103, 104, and 111).............. 3.3

3.4. Summary of Measured Illuminance on Colorado Avenue (poles 92, 93, and 94) ................... 3.3

3.5. Summary of Measured Illuminance on Amarillo Avenue (poles 94, 95, and 96) .................... 3.4

3.6. Illuminance Summary Comparison.............................................................................. 3.5

4.1. Illumination under LED Luminaire on Commercial Street at $100 \%$ and 50\% Power Levels .... 4.2

5.1. Annual Costs for Residential Fixtures ................................................................................ 5.2

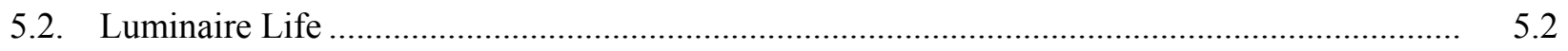

5.3. Summary of Base Case Inputs ................................................................................... 5.3

5.4. Net Present Value of Systems .......................................................................................... 5.3

5.5. Results of the Sensitivity Analysis on the In-Service Period of LEDs .................................. 5.4

5.6. Results of the Sensitivity Analysis on the Luminaire Cost..................................................... 5.5

5.7. Results of the Sensitivity Analysis on the Initial Efficacy of LEDs ...................................... 5.5

5.8. Results of the Sensitivity Analysis on the Maintenance Cost of LEDs .................................. 5.5

5.9. Net Present Value of Different LED Systems Replacing Different-Wattage HPS Systems....... $\quad 5.7$

5.10. Assumptions Underlying Installation and Payback Costs for Retrofitting HPS Luminaires with LED Luminaires

5.11. Economic Analysis of Dimming Control for LED or Induction........................................... 5.8 


\subsection{Introduction}

\subsection{Background}

The City Council of Palo Alto (Council) adopted the Climate Protection Plan (CPP) on December 3, 2007 , and set a goal of reducing greenhouse gas (GHG) emissions by $15 \%$ of 2005 levels, or 119,140 metric tons of $\mathrm{CO}_{2}$ by $2020 .{ }^{1}$ One of the short-term action items stemming from the CPP is to evaluate the cost-effectiveness of light-emitting diode (LED) technology for streetlights. LED technology offers the opportunity to reduce GHG emissions with operational cost savings including reduced energy usage. In addition to energy savings and reduction in GHG emissions, there are potential savings in maintenance costs. The City of Palo Alto currently has 6,300 high-pressure sodium (HPS) streetlights. Replacing all of these HPS streetlights with more energy-efficient luminaires could potentially reduce electricity usage by over $1.6 \mathrm{GWh}$ and avoid the emission of nearly 650 metric tons of GHG per year. ${ }^{2}$

In October 2008, Palo Alto's city manager provided a plan (CMR: 377:08) to the Council with specific short-, medium-, and long-term action items related to the implementation of LED street lighting in Palo Alto. The medium-term action items include the completion of a neighborhood LED streetlight demonstration by July 2010. The demonstration project would test and compare LED streetlight technologies in a residential neighborhood and would survey the community for feedback. ${ }^{3}$ In addition, the project scope would include a review of other local agency efforts to leverage the best information and research to date.

The demonstration project team was formed in September 2008, made up of staff from Utility Marketing Services, Resource Management, Engineering, and Operations. As part of the demonstration scope, the team decided to test both LED and induction streetlights, given that both technologies offer potential energy savings as well as maintenance cost savings. The City of Palo Alto contacted Pacific Northwest National Laboratory (PNNL) about participating in the U.S. Department of Energy (DOE) Solid-State Lighting GATEWAY Demonstration Program. As part of the GATEWAY program, PNNL assisted in luminaire selection (e.g., performed computer calculations), conducted field measurements of the lighting, and assisted in assessment of the performance of the test luminaires compared to existing luminaires and to the vendor specifications.

The test luminaires were installed on two residential streets and near the Palo Alto City Hall in the last week of June and first week of July in 2009. Baseline and post-installation field measurements were taken for lighting output and power draw consumption at the test sites.

\footnotetext{
${ }^{1} \mathrm{http}: / /$ www.cityofpaloalto.org/civica/filebank/blobdload.asp?BlobID=9986.

2 Assumes "energy-efficient" luminaire draws 40\% less power than the HPS luminaires with nominal wattage of 70 $\mathrm{W}, 100 \mathrm{~W}, 150 \mathrm{~W}$, and $250 \mathrm{~W}$; and the same annual operating hours of 4,100; 0.879 pounds of $\mathrm{CO}_{2}$ per $\mathrm{kWh} ; 1$ pound $=0.000453$ metric tons.

${ }^{3}$ The survey noted was undertaken, but its results are not included in this report.
} 


\subsection{Project Objectives}

The demonstration project is designed to evaluate the economic, technical, and operational feasibility of replacing the existing HPS streetlights with LED and induction light sources. Specifically, the following areas were evaluated as part of this project:

- energy and maintenance cost savings of LED and induction streetlights over the existing HPS streetlights

- illuminance of streets lighted by LED and induction streetlights compared to the streets lighted by the existing HPS streetlights

- cost-effectiveness of deploying a remote streetlight monitoring and dimming system.

The energy and maintenance cost savings are key inputs to the cost-effectiveness analysis of LED and induction streetlights. The performance metrics in the economic analysis includes simple payback as well as the net present value of cost savings over the lifetime of the LED and induction streetlight luminaires.

Of equal importance is the illumination level produced by the test streetlights. The City of Palo Alto does not currently have any streetlight criteria governing minimum illumination levels or restricting obtrusive light, so the alternative streetlight luminaires must only match the existing lighting levels from the HPS streetlights and have comparable or better control to minimize light trespass. In GATEWAY demonstrations it is typical to measure both the baseline and new lighting system illuminance. In this installation, the baseline measurement illuminance is more critical because of the city's lack of illuminance requirements. 


\subsection{Project Scope}

The scope of the demonstration project covers the evaluation of LED and induction streetlights as well as a remote monitoring and dimming system. The demonstration plan included the following tasks:

- replacing selected 70-W (nominal) HPS streetlight luminaires on a residential street with LED luminaires

- replacing selected 70-W (nominal) HPS streetlight luminaires on a residential street with induction streetlight luminaires

- replacing selected 150-W (nominal) HPS streetlight luminaires on a commercial street near City Hall with induction and LED luminaires - The LED and induction luminaires are to be deployed with a remote monitoring and dimming system.

\subsection{Luminaire Selection}

Numerous other municipalities and utilities have conducted demonstrations of alternatives to highintensity discharge (HID) light sources in roadway applications in California, many in the San Francisco Bay and Silicon Valley areas. ${ }^{1}$ These demonstrations have examined both LED and induction systems, and Palo Alto was interested in demonstrating the same technologies.

The test LED and induction luminaires were selected to match the illuminance levels of the HPS system. Pre-analysis was conducted using pole spacing of $125 \mathrm{ft}$ to $150 \mathrm{ft}$ and photometric data (.IES files) from multiple LED and induction manufacturers to estimate the average, maximum, and minimum illuminance levels.

Different-size LED test luminaires were selected to match each of 1) the average illuminance and 2) the minimum illuminance levels produced by the HPS system. The intent behind this approach was to obtain a visual comparison between the lower-power and higher-power LED products on different parts of the street. In this case, 20-LED luminaires were selected to match the minimum illuminance and 30LED luminaires to match the average illuminance of the 70-W HPS system. Unlike LED systems that can vary in light output by changing either the number of LEDs or the drive current, induction systems do not have that variability. The induction systems are limited by the larger wattage increments of the available lamps. Induction generators (the power supply) that can vary output are not common. Therefore, the induction system is selected on the criterion of saving energy (i.e., drawing less power than the baseline HPS system) and ideally produces approximately the same average illuminance on the roadway.

\subsubsection{Illuminance Requirements}

The City of Palo Alto does not have lighting criteria. As previously stated, the new luminaires were selected to match specific illumination characteristics of the existing system. However, a comparison to

\footnotetext{
${ }^{1}$ For more information about these other demonstrations: http://maps.google.com $/ \mathrm{maps} / \mathrm{ms}$ ?ie $=$ UTF $8 \& \mathrm{hl}=\mathrm{en} \& \mathrm{msa}=0 \& \mathrm{msid}=101199560702027194418.0004643 \mathrm{~d} 0 \mathrm{ec} 321746$ $\underline{6 \mathrm{f} 7 \mathrm{e} \& 11=37.387481,-121.96764 \& \mathrm{spn}=0.070788,0.131836 \& \mathrm{z}=13}$.
} 
IESNA RP-8-00 was also undertaken to get a sense of how the existing system compares with recommended practice. Illuminance values and uniformity ratios for roadway lighting are dependent on the following three variables: 1) Roadway Classification, 2) Pedestrian Conflict Area, and 3) Pavement Classification. A copy of Table 2: Illuminance Method-Recommended Values can be found in Appendix C of this report. ${ }^{2}$ The residential streets in this demonstration can be classified as "local" under the IESNA RP-8-00 definition. The residential streets in this demonstration can be classified as having low vehicle/pedestrian interactions. If Palo Alto adopted RP-8-00 as a lighting standard, the residential streets would likely be lighted to a maintained average illuminance of either 0.3 footcandles ( $\mathrm{fc}$ ) or $0.4 \mathrm{fc}$, depending on the roadway surface. The uniformity ratio (average-to-minimum) should be 6.0 or less.

\subsubsection{Existing High-Pressure Sodium Luminaires}

The City of Palo Alto standard roadway cobra head luminaires use lamps ranging from 70-W to $250-$ W HPS. The luminaires are manufactured by either General Electric or American Electric Lighting. ${ }^{3}$ The installed luminaire in this instance was the American Electric Lighting 315-07S (the Palo Alto Request for Proposal still lists the old catalog number of 313-5F3E3-DJ).

The luminaire has a dropped lens and, according to analysis via Photometric Toolbox, the luminaire has a Type III distribution and a "BUG" rating of B1-U2-G1. ${ }^{4}$ The HPS lamp was a nominal $70 \mathrm{~W}$, and the input power to the luminaire was measured in the field at $96 \mathrm{~W}$. According to a lamp catalog, the lamp had a nominal CCT of $2100 \mathrm{~K}$, a color rendering index (CRI) of 22, and produced 6,300 initial lumens. The luminaire had an efficiency of $67 \%$; emitted 4,192 lumens, and therefore had a luminaire efficacy of 44 lumens per watt $(\mathrm{lm} / \mathrm{W})$.

Figure 2-1 provides an indication of the vertical and horizontal distribution of the luminaire. The horizontal distribution is represented by a single intensity trace (the red line labeled " 2 " and shown in plan) for a downward-opening cone which intersects the point of maximum intensity. The vertical distribution is represented by a single intensity trace (the blue line labeled " 1 " and shown in elevation) within the vertical plan containing the point of maximum intensity.

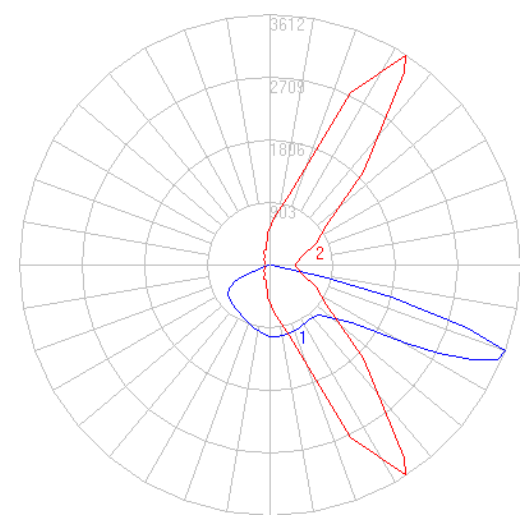

Figure 2-1. High-Pressure Sodium Luminaire Distribution

\footnotetext{
2 ANSI/IENSA RP-8-00, "Roadway Lighting” (Reaffirmed 2005).

${ }^{3}$ City of Palo Alto RFG09M002 Revised, January 15, 2004.

${ }^{4}$ Addendum A for IESNA TM-15-07 provides values for the backlight, uplight, and glare (BUG) ratings. These values are part of the new luminaire classification system (LCS) that formally replaced the cutoff classifications.
} 
It should be noted that the photometry from American Electric Lighting used in this report did not contain intensity information above $90^{\circ}$. Consequently, Photometric Toolbox did not provide LCS values for this file. Values above $90^{\circ}$ were assumed at 0 candelas. The Uplight value is $\mathrm{U} 2$ for this luminaire even though no light is emitted above $90^{\circ}$, the uplight rating looks at the lumens in both the Uplight Low $\left(90^{\circ}-100^{\circ}\right)$ and the Uplight High $\left(100^{\circ}-180^{\circ}\right)$ zones.

\subsubsection{New 20-LED Luminaires}

One of the LED luminaires used in this demonstration was manufactured by BetaLED (catalog code STR-TS-HT-017-LED-B-UL-SV-R). According to analysis via Photometric Toolbox, the luminaire has a Type II distribution and a BUG rating of B1-U0-G1. The LED luminaire has $201-\mathrm{W}$ LEDs operating at $525 \mathrm{~mA}$. According to the manufacturer, the nominal input power was $39 \mathrm{~W}$. The input power measured in the field was $42 \mathrm{~W}$. According to the manufacturer data sheet, the luminaire had a nominal CCT of $6000 \mathrm{~K}( \pm 500 \mathrm{~K})$, a CRI of 70 , and produced 2,474 initial lumens. Fixture efficiency is not applicable to this type of LED luminaire because the LEDs are an integrated component of the luminaire rather than a replaceable element, as with a lamp in a conventional fixture. The luminaire efficacy was $59 \mathrm{~lm} / \mathrm{W}$. Figure 2-2 provides an indication of the vertical and horizontal distribution of the luminaire.

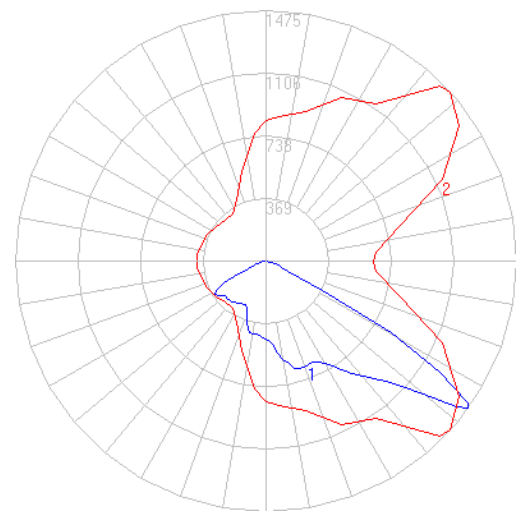

Figure 2-2. 20-LED Luminaire Distribution

It should be noted that the photometry in this report for the LEDway 20-LED luminaire was derived from a modified .IES file. BetaLED, the manufacturer, sent the photometry for a 40-LED luminaire operating at $525 \mathrm{~mA} .^{5}$ Using Photometric Toolbox, we used a 0.5 multiplier in the multiplier field to modify the photometric file. The multiplier field is a standard field in .IES files per LM-63.

\subsubsection{New 30-LED Luminaires}

Another LED luminaire used in this demonstration was manufactured by BetaLED (catalog code STR-TS-HT-034-LED-B-UL-SV-R). According to analysis via Photometric Toolbox, the luminaire has a Type II distribution and a BUG rating of B1-U1-G1. The LED luminaire has 30 1-W LEDs operating at $525 \mathrm{~mA}$. According to the manufacturer, the input power was $55 \mathrm{~W}$. The input power measured in the field was $54 \mathrm{~W}$. According to the manufacturer data sheet, the luminaire had a nominal CCT of $6000 \mathrm{~K}$ $( \pm 500 \mathrm{~K})$, a CRI of 70, and produced 3,712 initial lumens. Again, fixture efficiency is not applicable to

\footnotetext{
${ }^{5}$ Electronic correspondence from BetaLED with PNNL on January 5, 2010.
} 
this type of LED luminaire. The luminaire efficacy was $69 \mathrm{~lm} / \mathrm{W}$. Figure 2.3 provides an indication of the vertical and horizontal distribution of the luminaire.

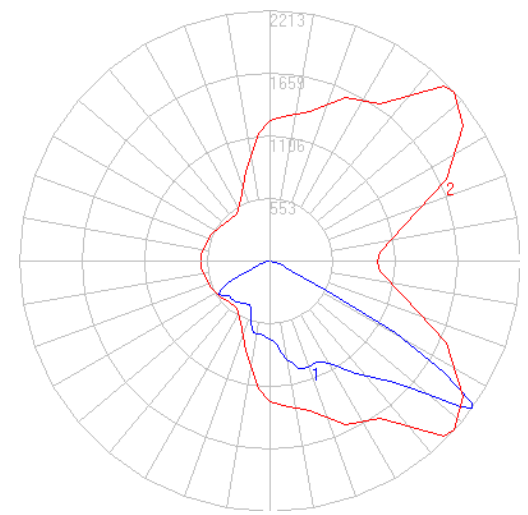

Figure 2-3. 30-LED Luminaire Distribution

It should be noted that the photometry in this report for the LEDway 30-LED luminaire was derived from a modified .IES file. BetaLED, the manufacturer, sent the photometry for a 40-LED luminaire operating at $525 \mathrm{~mA} .{ }^{6}$ Using Photometric Toolbox, we modified the photometric file from the manufacturer by using a 0.75 multiplier in the multiplier field. The multiplier field is a standard field in .IES files per LM-63.

\subsubsection{New Induction Luminaires}

The induction luminaire used in this demonstration was manufactured by Deco Lighting (catalog code D8622i-86-50-277-SL-PC). The luminaire has a flat lens and, according to analysis via Photometric Toolbox, the luminaire has a Type II distribution and a BUG rating of B2-U1-G2. According to the manufacturer, the input power was $86 \mathrm{~W}$. The input power measured in the field was $90 \mathrm{~W}$. The lamp has a nominal CCT of $5000 \mathrm{~K}$ and a CRI of 80 and produces 7,360 lumens. The luminaire has an efficiency of 79\%; emitted 5,794 lumens, and therefore the luminaire efficacy was $64 \mathrm{~lm} / \mathrm{W}$. Figure 2.4 provides an indication of the vertical and horizontal distribution of the luminaire.

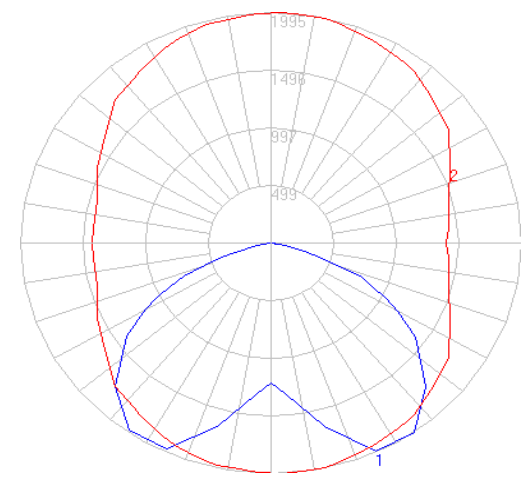

Figure 2-4. Induction Luminaire Distribution

\footnotetext{
${ }^{6}$ Electronic correspondence from BetaLED with PNNL on January 5, 2010.
} 
It should be noted that the photometry used to create the .IES file for Deco Lighting and analyzed by Photometric Toolbox for this demonstration was not based on laboratory measurements but rather on computer simulations. ${ }^{7}$ This luminaire was not actually tested by either the manufacturer or an independent third party.

\subsubsection{Backlight, Uplight, and Glare Ratings}

In 2007, the IESNA published Addendum A for TM-15-07, providing values for the backlight, uplight, and glare (BUG) ratings. These values are part of the new luminaire classification system (LCS) that formally replaced the cutoff classifications. The values in Table 2.1 compare the BUG ratings and the luminaire output (lumens) of the luminaires used in this demonstration.

Table 2.1. Backlight, Uplight, and Glare Ratings

\begin{tabular}{lcccc}
\hline Source & $\begin{array}{c}\text { Backlight } \\
(\mathrm{B})\end{array}$ & $\begin{array}{c}\text { Uplight } \\
(\mathrm{U})\end{array}$ & $\begin{array}{c}\text { Glare } \\
(\mathrm{G})\end{array}$ & $\begin{array}{c}\text { Luminaire } \\
\text { Lumens }\end{array}$ \\
\hline HPS & $\mathrm{B} 1$ & $\mathrm{U} 2$ & $\mathrm{G} 1$ & 4,192 \\
20-LED & $\mathrm{B} 1$ & $\mathrm{U} 0$ & $\mathrm{G} 1$ & 2,474 \\
30-LED & $\mathrm{B} 1$ & $\mathrm{U} 1$ & $\mathrm{G} 1$ & 3,715 \\
Induction & $\mathrm{B} 2$ & $\mathrm{U} 1$ & $\mathrm{G} 2$ & 5,794 \\
\hline
\end{tabular}

Unlike the cutoff classifications that focus on relative proportions of the luminaire distribution, LCS focuses on the absolute number of lumens emitted in different zones by the luminaire. Therefore, if a luminaire emits more overall light than another alternative, it may also have higher individual $\mathrm{B}, \mathrm{U}$, or $\mathrm{G}$ values. Of the luminaires in this demonstration, the induction luminaire emits the most backlight (which is evident in Figure 2-4). In contrast, the HPS luminaire emits the most uplight of the three. Both of these values indicate that light is not being directed to the roadway where it is intended; thus, some the lumens generated are essentially wasted. These lumens are wasted in part because it is more difficult to create efficiently controlled optical systems for large omnidirectional light sources (i.e., induction or HPS lamps) than it is for small directional sources (i.e., LEDs).

\subsection{Site Selection}

Site selection is always a complicated process due to multiple and often conflicting needs. For example, in roadway lighting the site needs to be sufficiently well traveled to offer the potential for user feedback. However, more roadway traffic increases the difficulty of conducting lighting measurements. Another issue of concern is the presence and size of buildings or sites adjacent to the roadway. Spill light from buildings or parking lots along the roadway complicate and skew measurements and user perception. The sites described in this section were selected after a careful review of the different roads and adjacent properties, through discussions with Palo Alto personnel, and use of Google Earth software.

\footnotetext{
${ }^{7}$ Electronic correspondence between Deco Lighting and PNNL on September 21, 2009.
} 


\subsubsection{Residential Site}

Based on the recommendations of the Community Environmental Action Partnership (CEAP), the residential streets of Colorado Avenue and Amarillo Avenue were selected for the demonstration test sites. The CEAP was created by a joint city and community group team to bring the various segments of the community together to share knowledge, build mutual understanding, leverage resources, and both create and implement innovative environmental solutions. The CEAP recommended these streets due to previous lighting issues. Of benefit for testing is the fact that these streets are near parallel in this section of Palo Alto.

Luminaires with 20 LEDs were installed on pole numbers 103, 104, and 111 located on Colorado Avenue between Greer Road and Bayshore Road. A park and an apartment complex are adjacent to this site (Figure 2.5). However, lighting from these adjacent properties did not significantly affect the lighting on the street.

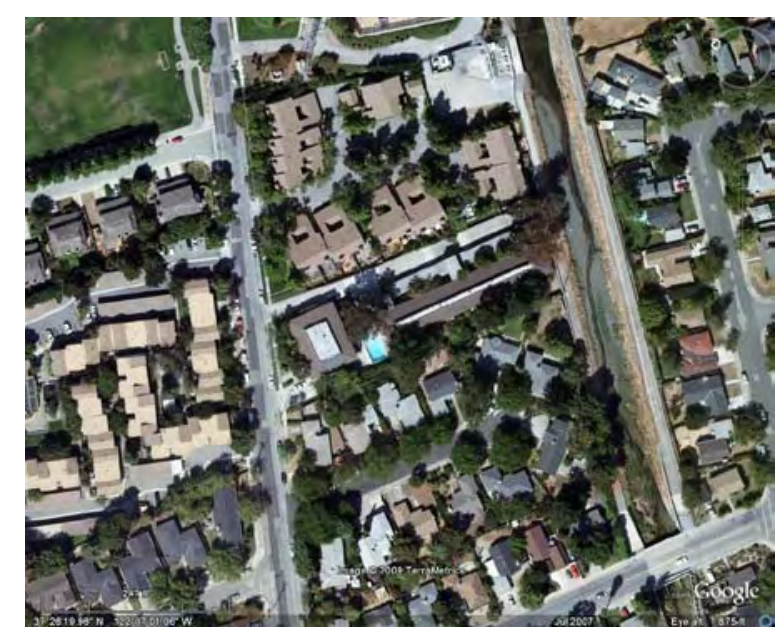

Figure 2-5. 20-LED Site

Luminaires with 30 LEDs were installed on pole numbers 92, 93, 94, and 95 located on Colorado Avenue between Louis Road and Greer Road (Figure 2.6). Friends Nursery School is located adjacent to this site. However, lighting from this site did not significantly affect the lighting on the street. 


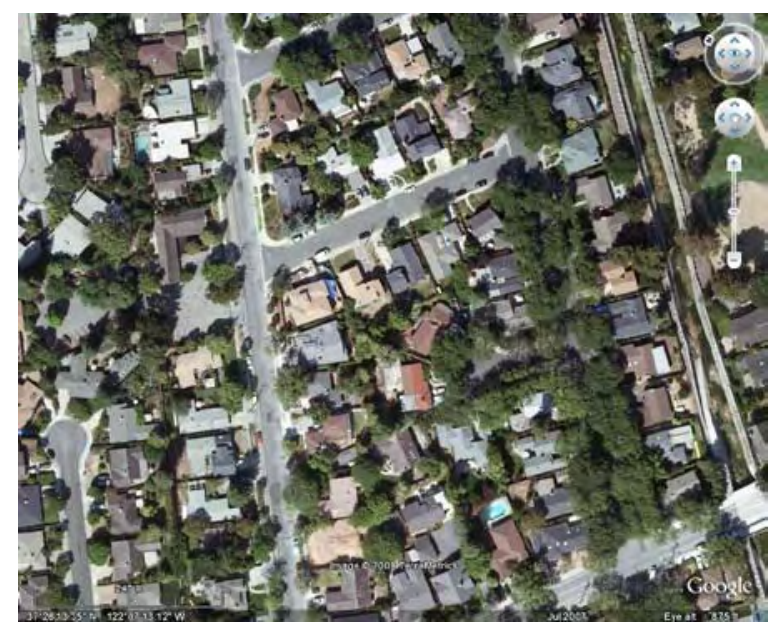

Figure 2-6. 30-LED Site

The induction luminaires were installed on pole numbers 94, 95, and 96 located on Amarillo Avenue between Louis Road and Greer Road (Figure 2.7). This site was selected because it was sufficiently far away from Ohlone Elementary School where light from the site could impact the measurements. Pole spacing was roughly equidistant, and the tree canopy was notable but did not significantly cover the street.

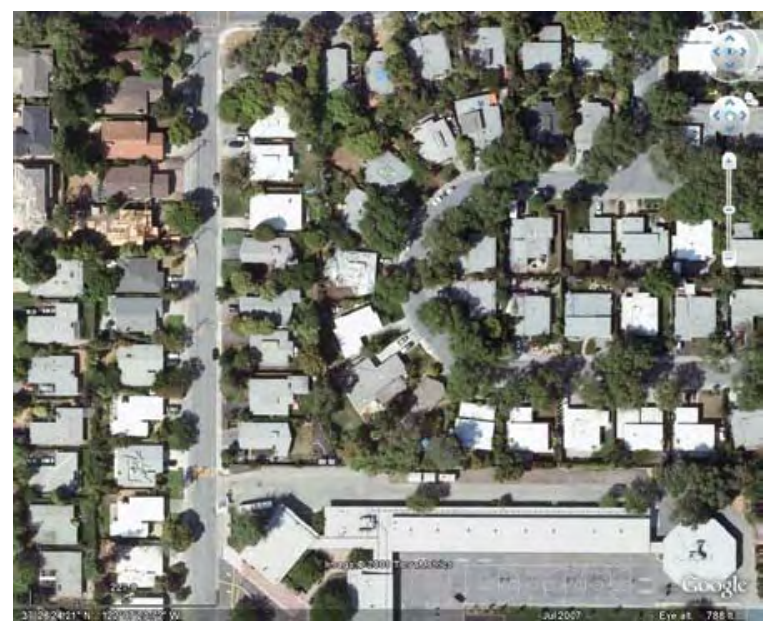

Figure 2-7. Induction Luminaire Site

\subsubsection{Commercial Site}

The City of Palo Alto was interested in examining replacing the existing lighting in the commercial center of Palo Alto. The existing luminaires have larger lumen outputs than the residential luminaires and thus also higher wattages. Rather than replicate the same test in the residential area, Palo Alto chose to replace only a handful of luminaires and examine the use of a remote monitoring and dimming system with the LED and induction streetlights.

For the commercial test site, staff selected Bryant and Ramona Street near City Hall. In the center of Figure 2-8 is City Hall, with Bryant Street on the left of City Hall and Ramona Street on the right. 
Remote monitoring and dimming controls were installed in both the LED and induction luminaires for testing.

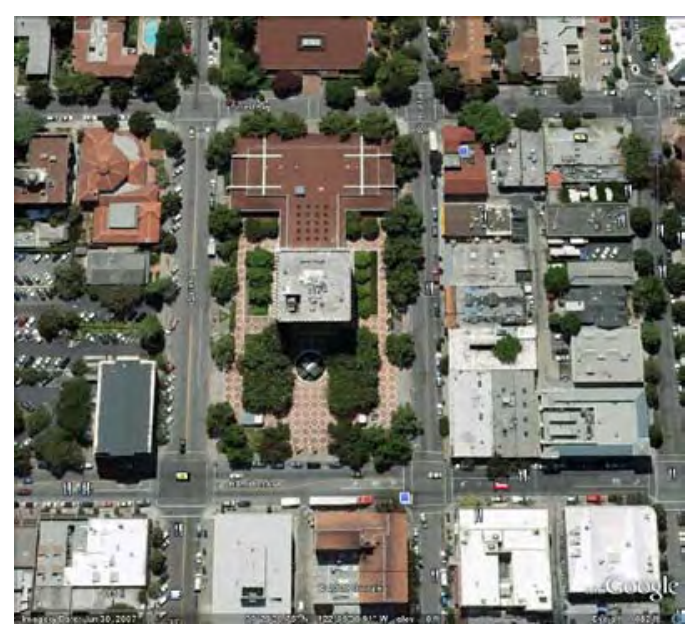

Figure 2-8. Commercial Test Site 


\subsection{Methodology and Measurement Results}

Computer modeling provides useful information but there are always differences when the luminaires are installed and measured in the field. Illuminance measurements were taken in the field per RP-8-00 recommendations. ${ }^{1}$ Power measurements were also taken to determine the energy usage of the luminaires.

\subsection{Installation}

Prior to their replacement, the existing cobra heads were cleaned, relamped, and operated for over 100 hours $^{2}$ before baseline illumination and power measurements were taken. Following this initial measurement, the HPS luminaires were replaced with the both the induction and LED luminaires; power and illumination measurements were then repeated.

\subsection{Power and Energy}

Power measurements for both the baseline and new luminaires were taken at the same point in the circuit. Measurements were taken for many luminaires, and the average values are presented in Table 3.1 Palo Alto supplies a nominal $240 \mathrm{~V}$ to the roadway luminaires.

Table 3.1. Power Measurements

\begin{tabular}{lcccc}
\hline Source & Voltage $(\mathrm{V})$ & Current $(\mathrm{A})$ & Power Factor & Power $(\mathrm{W})$ \\
\hline HPS & 243.1 & 0.44 & 0.94 & 96 \\
20-LED & 240.7 & 0.19 & 0.89 & 42 \\
30-LED & 231.5 & 0.27 & 0.87 & 54 \\
Induction & 241.4 & 0.41 & 0.93 & 90 \\
\hline
\end{tabular}

Each luminaire is controlled via photocell integral to the luminaire. Operating hours were assumed to average 11.2 hours per day because of the use of a photocell. Table 3.2 lists the assumed energy usage of the different lighting systems based on the power for each luminaire type (from Table 3.1) and the operating hours. A representative 100 were selected to show sample magnitude of converting from the baseline HPS to the other technology.

In summary, all three lighting systems examined on the residential streets saved energy ranging from $6 \%$ to $56 \%$ compared to the baseline HPS system.

\footnotetext{
${ }^{1}$ IESNA RP-8-00, “American National Standard Practice for Roadway Lighting” (Reaffirmed 2005).

2 IESNA LM-54-99, "IESNA Guide to Lamp Seasoning," recommends operating discharge lamps for 100 hours so that measurements can establish initial or rated lumens. The output of HID lamps in the 0- to 10-hour range is between $8 \%$ and $10 \%$ lower than rated.
} 
Table 3.2. Energy Calculations

\begin{tabular}{lcccccc}
\hline Quantity & Source Type & $\begin{array}{c}\text { Luminaire } \\
\text { Power (W) }\end{array}$ & $\begin{array}{c}\text { Total } \\
\text { Power (W) }\end{array}$ & Hours & $\begin{array}{c}\text { Energy } \\
(\mathrm{kWh})\end{array}$ & Reduction \\
\hline 100 & HPS & 96 & 9,600 & 4,100 & 39,360 & N/A \\
100 & 20 LEDs & 42 & 4,200 & 4,100 & 17,220 & $56 \%$ \\
100 & 30 LEDs & 54 & 5,400 & 4,100 & 22,140 & $44 \%$ \\
100 & Induction & 90 & 9,000 & 4,100 & 36,900 & $6 \%$ \\
\hline
\end{tabular}

\subsection{Illuminance}

Illuminance is the preferred metric for verifying roadway lighting system performance. All of the measured illuminance values can be found in Appendix A of this report.

Illuminance was measured after 10:00 pm PST on July 6 (baseline) and on July 7 (LED and induction) along grids spaced $\approx 16 \mathrm{ft} \times \approx 8 \mathrm{ft}$ (specific grids varied per street). The temperature was $62^{\circ} \mathrm{F}$, and the weather conditions were dry, clear, and post-full moon. Other environmental conditions included the fact that a direct view of the moon was mostly blocked by nearby houses and trees, and most porch lights were on in the neighborhood. Tables 3.3 through 3.5 provide summary results of the measured illuminance values including average, maximum, and minimum illuminance.

As stated in Section 2.1.1, if Palo Alto adopted IESNA RP-8-00 for illuminance requirements, the streets should be lighted to an average of either 0.3 or $0.4 \mathrm{fc}$ (depending on the pavement reflectance), and the uniformity (average-to-minimum) ratio should be 6.0 or less. The tables of illuminance values in the following sections include standard uniformity metrics of maximum:minimum ( $\mathrm{max} / \mathrm{min}$ ) and average:minimum (avg/min). Additional uniformity metrics provided in these tables include the standard deviation (Std. Dev.) and coefficient of variation (CV). The CV is the Std. Dev. divided by the mean. These relatively non-standard uniformity metrics provide an indication of the consistency of the measured data as a whole, reducing sensitivity to single measurement points.

\subsubsection{0-LED luminaires}

The 20-LED system was designed to match the minimum illuminance produced by the HPS system. For this measured roadway, the minimum HPS value found was $0.03 \mathrm{fc}$, and the minimum LED value was $0.02 \mathrm{fc}$. Table 3.3 provides the illuminance of the HPS and LED systems, both measured and as calculated.

The illuminance from the LED lighting system produced 54\% of the average illuminance produced by the HPS lighting system, which is similar to the $56 \%$ reduction in power from the HPS to the LED system. The maximum illuminance values from the LED system were only $38 \%$ of the HPS system. The Std. Dev. and CV are strong indicators of variability within a population of data; the lower the value, the less variation about the average. The LED system showed less variation among illuminance values in both metrics.

\footnotetext{
${ }^{3}$ According to Palo Alto, the city operates its luminaires for 11.2 hours per day $\times 365.25$ days $=4,100$ hours per year.
} 
Table 3.3. Summary of Measured Illuminance on Colorado Avenue (poles 103, 104, and 111)

\begin{tabular}{lcccccc} 
& \multicolumn{3}{c}{ HPS Values } & \multicolumn{3}{c}{ LED Values } \\
\cline { 2 - 7 } & Measured & Calculated & Difference & Measured & Calculated & Difference \\
\hline Average & $0.44 \mathrm{fc}$ & $0.33 \mathrm{fc}$ & $25 \%$ & $0.24 \mathrm{fc}$ & $0.23 \mathrm{fc}$ & $4 \%$ \\
Max & $2.64 \mathrm{fc}$ & $1.67 \mathrm{fc}$ & $37 \%$ & $1.02 \mathrm{fc}$ & $0.88 \mathrm{fc}$ & $14 \%$ \\
Min & $0.03 \mathrm{fc}$ & $0.00 \mathrm{fc}$ & N/A & $0.02 \mathrm{fc}$ & $0.01 \mathrm{fc}$ & $50 \%$ \\
Avg/Min & $15: 1$ & N/A & --- & $12: 1$ & $23: 1$ & --- \\
Max/Min & $88: 1$ & N/A & --- & $51: 1$ & $88: 1$ & --- \\
Std. Dev. & $0.54 \mathrm{fc}$ & $0.34 \mathrm{fc}$ & $37 \%$ & $0.26 \mathrm{fc}$ & $0.26 \mathrm{fc}$ & $0 \%$ \\
Number of & 92 & 92 & --- & 92 & 92 & -- \\
Points & 1.22 & 1.03 & $16 \%$ & 1.08 & 1.12 & $-4 \%$ \\
$\begin{array}{l}\text { Coefficient of } \\
\text { Variation }\end{array}$ & & & & & & \\
\hline
\end{tabular}

\subsubsection{0-LED Luminaires}

The illuminance from the 30-LED lighting system produced $16 \%$ higher average illuminance than the HPS lighting system, although maximum illuminance was $14 \%$ less. As a result, the Std. Dev. for the LED system was greater than for the HPS data but the two systems had similar CVs.

Table 3.4. Summary of Measured Illuminance on Colorado Avenue (poles 92, 93, and 94)

\begin{tabular}{lcccccc} 
& \multicolumn{3}{c}{ HPS Values } & \multicolumn{3}{c}{ LED Values } \\
\cline { 2 - 7 } & Measured & Calculated & Difference & Measured & Calculated & Difference \\
\hline Average & $0.36 \mathrm{fc}$ & $0.52 \mathrm{fc}$ & $-31 \%$ & $0.43 \mathrm{fc}$ & $0.48 \mathrm{fc}$ & $-10 \%$ \\
\hline Max & $1.68 \mathrm{fc}$ & $2.09 \mathrm{fc}$ & $-20 \%$ & $1.47 \mathrm{fc}$ & $1.37 \mathrm{fc}$ & $7 \%$ \\
Min & $0.02 \mathrm{fc}$ & $0.01 \mathrm{fc}$ & $50 \%$ & $0.01 \mathrm{fc}$ & $0.04 \mathrm{fc}$ & $-300 \%$ \\
Avg/Min & $18: 1$ & $52: 1$ & --- & $43: 1$ & $12: 1$ & --- \\
Max/Min & $84: 1$ & $209: 1$ & --- & $147: 1$ & $34: 1$ & --- \\
\hline Std. Dev & $0.38 \mathrm{fc}$ & $0.50 \mathrm{fc}$ & $-24 \%$ & $0.44 \mathrm{fc}$ & $0.41 \mathrm{fc}$ & $7 \%$ \\
Number of & 88 & 111 & --- & 88 & 111 & --- \\
Points & 1.05 & 0.97 & $8 \%$ & 1.04 & 0.85 & $22 \%$ \\
Coefficient of & & & & & & \\
Variation & & & & & & \\
\hline
\end{tabular}

\subsubsection{Induction Luminaires}

Average illuminance from the induction lighting system was $15 \%$ lower than that of the HPS system, while maximum illuminance was $13 \%$ greater. The Std. Dev. and CV for the induction system indicate 
considerably greater variation among illuminance values across the measurement grid compared to the HPS.

Table 3.5. Summary of Measured Illuminance on Amarillo Avenue (poles 94, 95, and 96)

\begin{tabular}{lcccccc} 
& \multicolumn{3}{c}{ HPS Values } & \multicolumn{3}{c}{ Induction Values } \\
\cline { 2 - 7 } & Measured & Calculated & Difference & Measured & Calculated & Difference \\
\hline Average & $0.27 \mathrm{fc}$ & $0.36 \mathrm{fc}$ & $-33 \%$ & $0.23 \mathrm{fc}$ & $0.53 \mathrm{fc}$ & $-130 \%$ \\
Max & $1.34 \mathrm{fc}$ & $2.29 \mathrm{fc}$ & $-71 \%$ & $1.52 \mathrm{fc}$ & $3.39 \mathrm{fc}$ & $-123 \%$ \\
Min & $0.01 \mathrm{fc}$ & $0.01 \mathrm{fc}$ & $0 \%$ & $0.01 \mathrm{fc}$ & $0.01 \mathrm{fc}$ & $0 \%$ \\
Avg/Min & $27: 1$ & $36: 1$ & --- & $23: 1$ & $53: 1$ & --- \\
Max/Min & $134: 1$ & $229: 1$ & --- & $152: 1$ & $339: 1$ & --- \\
Std. Dev & $0.24 \mathrm{fc}$ & $0.42 \mathrm{fc}$ & $-75 \%$ & $0.29 \mathrm{fc}$ & $0.82 \mathrm{fc}$ & $-183 \%$ \\
Number of & 84 & 92 & --- & 86 & 92 & --- \\
Points & 0.90 & 1.17 & $-30 \%$ & 1.23 & 1.54 & $-25 \%$ \\
Coefficient of & & & & & & \\
Variation & & & & & &
\end{tabular}

\subsubsection{Illuminance Review}

In Tables 3.3 through 3.5, significant differences are evident between the measured and calculated values, with the calculated values generally being higher. The fixtures were freshly relamped and seasoned for this study; however, several additional factors may be contributing to such a result, including any or all of the following:

- tree canopies blocking light

- dirt buildup on the HPS system - The lenses were cleaned with a damp rag during this evaluation but may have yellowed or become etched from insect-introduced acids over time.

- different ballast type than modeled, or variations in performance due to different ages of ballasts

- electrical issues, such as voltage variation due to deteriorated wiring in the poles

- manufacturing tolerances between HPS lamps, and possibly different brands of lamps among fixtures.

- lamp orientation - HID lamps do not operate as well horizontally as vertically, and HPS lamp manufacturers typically report only lumen values for the HPS lamp oriented vertically.

- the fact that the induction luminaire was not actually photometered.

Table 3.6 summarizes the illuminance metrics for the three different sites. Only two of the HPS systems met the IESNA RP-8-00 average illuminance, even after the results were rounded to one significant digit. 
Table 3.6. Illuminance Summary Comparison

\begin{tabular}{lccccccc} 
& \multicolumn{2}{c}{ Colorado 1 } & \multicolumn{2}{c}{ Colorado 2} & \multicolumn{2}{c}{ Amarillo } & \multirow{2}{*}{ RP-8-00 } \\
\cline { 2 - 7 } Average & HPS & 20 -LED & HPS & 30 -LED & HPS & IND & \\
\cline { 2 - 7 } Minimum & $0.44 \mathrm{fc}$ & $0.24 \mathrm{fc}$ & $0.36 \mathrm{fc}$ & $0.43 \mathrm{fc}$ & $0.27 \mathrm{fc}$ & $0.23 \mathrm{fc}$ & $0.4 \mathrm{fc}$ \\
Avg/Min & $0.03 \mathrm{fc}$ & $0.02 \mathrm{fc}$ & $0.02 \mathrm{fc}$ & $0.01 \mathrm{fc}$ & $0.01 \mathrm{fc}$ & $0.01 \mathrm{fc}$ & N/A \\
Std. Dev. & $15: 1$ & $12: 1$ & $18: 1$ & $43: 1$ & $27: 1$ & $23: 1$ & $6: 1$ \\
$\begin{array}{l}\text { No. of pts } \\
<0.05\end{array}$ & $0.54 \mathrm{fc}$ & $0.26 \mathrm{fc}$ & $0.38 \mathrm{fc}$ & $0.44 \mathrm{fc}$ & $0.24 \mathrm{fc}$ & $0.29 \mathrm{fc}$ & N/A \\
CV & 8 & 26 & 19 & 27 & 6 & 32 & N/A \\
\hline
\end{tabular}

No one system measured (HPS, LED, or induction) met the avg/min uniformity metric of 6:1 as prescribed in RP-8-00. Using avg/min metric may not provide entirely accurate information about the lighting systems, however, because, for example, it can be driven by low minimum values present in only one or a few spots. In Palo Alto, for example, each site had many mature trees with shadowing caused by branches and leaves, often leading to extremely low values in isolated areas.

Upon first glance at the HPS and 30-LED installation comparison, the LED might appear to have worse uniformity because it produced a higher average illuminance while having a minimum identical to that of the HPS (both minimums caused by shadowing rather than lumen output). The CV for these two systems is virtually identical and the Std. Dev. varies only slightly. In this case, the latter two measures provide a better indication of variability within the measured space and, in fact, show that the two systems are essentially equivalent in terms of uniformity.

Palo Alto was interested in reviewing other metrics as well as those already reported-for example, the number of points with values below the illuminance possible from the moon. In the absence of electric lighting, the moon is the primary luminous source, and this report assumes $0.05 \mathrm{fc}$ as typical illuminance from the moon on the ground. ${ }^{4}$ Comparing illuminance to moonlight is not a new idea. Early (turn of the 20th century) roadway lighting efforts used the moonlight as a benchmark to judge whether the electric lighting system was doing a sufficient job. Although this metric has become somewhat antiquated by current standards of electrification, illumination, and resulting sky glow, it is reappearing in some circles in the context of dark sky considerations.

The non-HPS systems had more points below $0.05 \mathrm{fc}$ than the HPS across the board, although all of the systems had multiple points beneath this level. In particular, the second section of Colorado Avenue (where the luminaires are slightly closer together) had a significant number of points for all of the source types, indicating that pole spacing, obstructions, and possibly other factors are skewing the illuminance in this section rather than luminaire distribution.

\footnotetext{
${ }^{4} 0.05 \mathrm{fc}$ is an approximate average value. The value will vary by the phase of the moon, season, and location on Earth. A cursory search of the literature found reported values ranging from 0.01 to $0.1 \mathrm{fc}$.
} 



\subsection{Commercial Site and Monitoring System Evaluation}

In addition to the residential street light evaluation, Palo Alto was interested in examining new light sources and control devices for higher-traffic commercial streets. However, due to cost, equipment availability, and logistics, a methodical evaluation equivalent to that of the residential streets could not be conducted for the commercial street location. In this case, the focus was placed on the control system to gain information about the economics and performance of that system component.

The streetlight control system consists of a communication microchip that is pre-installed with each luminaire, a segment controller that communicates with the individual streetlight luminaires over the power line, and a software system that monitors and controls the streetlight fixtures.

\subsection{Evaluation of Commercial Streetlight with HPS Luminaires}

Originally, the commercial site was planned to evaluate dimmable versions of HPS, induction, and LED systems along with a monitoring system. Ultimately, the HPS product was not installed because the cost of the electronic and dimmable HPS ballast approached $\$ 300$, exceeding the cost of an entirely new HPS luminaire. Meanwhile, the HPS electronic ballast manufacturer states a $6 \%$ ballast loss for its ballasts, which translates to a ballast input wattage of $159 \mathrm{~W}$ for a nominal $150-\mathrm{W}$ lamp. Typical input power for magnetic HPS ballasts ranges from $170 \mathrm{~W}$ to $196 \mathrm{~W}$, so the energy savings of the electronic ballast compared to the magnetic ballast would be between $6 \%$ and $19 \%$, depending on the specific magnetic ballast originally installed when the dimming ballast is operating at full output. The high cost of the power supply meant that the energy savings would have to be significant to be economically feasible. Between the logistical issues associated with actually acquiring the HPS ballast and the limited energy savings at a significant cost premium, the city chose to abandon this part of the evaluation.

\subsection{Evaluation of Commercial Streetlight with LED Luminaires}

LED luminaires containing 60 LEDs (BetaLED catalog code BLD-STR-TS-HT-051-LED-B-UL-SV$\mathrm{R}$ w/ 0-10V dimming driver) using LONworks control equipment were installed on two existing poles on Bryant Street. As a commercial street, more light is needed and the baseline HPS fixture uses a higher wattage HPS lamp. Therefore, the LED luminaires on this street contained 60 LEDs rather than the 20 or 30 LEDs in the residential streets. Measured values for this system are listed in Table 4.1.

LED luminaires in general increase in efficacy as their power draw is decreased. In this case, reducing the power by $50 \%$ reduced average illuminance by only $43 \%$. Uniformity also improved as the LED luminaires dimmed because the maximum value drops more rapidly than the minimum value. In this case, the maximum dropped in correspondence with the reduction in power consumption, $50 \%$, while the minimum dropped by only $20 \%$, and the ratios of these values improved accordingly. It is unlikely that the distribution changed as the product was dimmed, more likely that meter accuracy decreases as the illuminance gets very low. 
Table 4.1. Illumination under LED Luminaire on Commercial Street at $100 \%$ and $50 \%$ Power Levels

\begin{tabular}{lccc} 
& LED @ $100 \%$ Power & LED @ $50 \%$ Power & \% Change \\
\hline Average & $1.12 \mathrm{fc}$ & $0.64 \mathrm{fc}$ & $-43 \%$ \\
Maximum & $2.57 \mathrm{fc}$ & $1.29 \mathrm{fc}$ & $-50 \%$ \\
Minimum & $0.15 \mathrm{fc}$ & $0.12 \mathrm{fc}$ & $-20 \%$ \\
Avg/Min & $7.43: 1$ & $5.31: 1$ & NA \\
Max/Min & $17.13: 1$ & $10.75: 1$ & NA \\
Std. Dev. & $0.71 \mathrm{fc}$ & $0.33 \mathrm{fc}$ & -- \\
Number of Points & 66 & 66 & NA \\
Coefficient of Variation & 0.63 & 0.52 & --- \\
\hline
\end{tabular}

\subsection{Evaluation of Commercial Streetlight with Induction Luminaires}

Induction luminaires (Deco Lighting catalog code D8624i-165-50 w/ 0-10V dimmable generator) using LONworks control equipment were installed on two existing poles on Ramona Street. However, the project team had initial problems synchronizing the communication between the luminaires and the monitoring software; therefore, no illuminance measurements were taken during the evening of the site visit. The communication issue was subsequently resolved, and visual evaluation confirmed the induction luminaires were operating as expected. However, due to the problems during the measurement period, neither illuminance nor power measurements were taken. Therefore, the relationship between dimming and illuminance could not be established for this system.

\subsection{Summary of Evaluation of Commercial Streetlight Pilot}

Networked streetlighting control systems are still in a relatively early stage of their development. As such, it appears there are some ongoing technical and cost issues remaining to be worked out before they will be able to achieve widespread implementation. However, the opportunity for additional energy savings and other capability improvement appears very promising once these early-stage issues are resolved.

An important criterion for selecting test sites using this type of remote monitoring system is that the streetlights must be uniformly connected to the same power leg of the electrical circuit since the communications with the luminaires occur through the power line. Because this has not been a consideration with earlier installations of street lighting, it is likely that bringing the existing inventory up to a consistent basis will present a significant (although one-time) additional hurdle in the implementation of this design. 


\subsection{Economics}

The demonstration evaluated the economics of replacing HPS luminaires of different wattages with LED and induction luminaires for both retrofit and new construction scenarios. The metrics used to compare the economics include simple payback and net present value (NPV) of cost savings. The analysis also investigated the sensitivity of the NPV for replacing HPS with LED luminaires to account for uncertainty in the expected life, luminaire initial cost, ongoing maintenance costs, and power usage of LED luminaires. Finally, the economics of remote monitoring and dimming control is also evaluated.

\subsection{Cost Assumptions}

For the economic analysis, the cost components include

- initial cost of new luminaires

- installation costs (assumed at $\$ 100 /$ luminaire)

- energy cost (4,100 operating hours at $\$ 0.08 / \mathrm{kWh})$

- material replacement costs

- GHG emissions costs (assumed at \$20/ton, escalated at 5\%/year beginning in 2008)

- recycling costs for the HPS and induction lamps to recover the mercury content, which is separately treated as universal waste - Recycling costs do not apply to LEDs because they do not contain mercury. Although materials in LED products can and should be recycled, the recycling is not mandated so the costs were not factored into this analysis.

For material replacement costs, the retrofit scenario includes the replacement cost of the HPS lamp every 5 years, the ballast every 15 years, the igniter every 20 years, the HPS luminaire (i.e., the housing of the lamp) every 25 years, and the photocell every 15 years. For LED and induction streetlights, it is assumed that the photocell is replaced every 15 years. Under the new construction scenario, however, material replacement costs for the HPS include only the lamp and photocell.

Current HPS maintenance costs covers group replacements for HPS lamps, as well as repairing knock-downs, dig-ins, bad wires, and other components. The City of Palo Alto Utilities estimates that only $30 \%$ of streetlight maintenance costs can be allocated to lamp replacements; therefore converting to a light source with a longer life than HPS lamps could reduce annual maintenance costs by $30 \%$.

GHG emissions costs are included in the cost analysis to comply with the Climate Protection Plan adopted by the City Council of Palo Alto in 2007, which requires the use of a carbon adder when making investment decisions in energy efficiency and renewable energy resources. The carbon adder was established at $\$ 20$ per ton of $\mathrm{CO}_{2}$ increasing at a rate of $5 \%$ per year beginning in 2008. The GHG intensity of the avoided electricity is assumed to be $0.879 \mathrm{lb} \mathrm{CO} / \mathrm{kWh}$.

Table 5.1 summarizes the estimated annual cost components for a single unit of 70-W HPS and the replacement LED and induction luminaires. The analysis reviewed the economics of replacing $70-\mathrm{W}$ HPS luminaires with both 20-LED and 30-LED luminaires as well as induction luminaires. The cost 
figures assume 2010 as the base year and are escalated at $2 \%$ per year. For all cost calculations, a tax rate of $9.25 \%$ is applied to the material costs.

Table 5.1. Annual Costs for Residential Fixtures

\begin{tabular}{lcccc} 
& $70 \mathrm{~W}$ HPS & 20 LEDs & 30 LEDs & Induction \\
\hline Initial luminaire cost & $\$ 78.00$ & $\$ 350.00$ & $\$ 420.00$ & $\$ 459.00$ \\
Annual energy cost & $\$ 31.82$ & $\$ 13.78$ & $\$ 18.37$ & $\$ 29.52$ \\
Annual material replacement cost & $\$ 10.84$ & $\$ 0.61$ & $\$ 0.61$ & $\$ 0.61$ \\
\hline Annual maintenance cost & $\$ 55.56$ & $\$ 38.90$ & $\$ 38.90$ & $\$ 38.90$ \\
Annual lamp recycling cost & $\$ 0.40$ & $\$ 0$ & $\$ 0$ & $\$ 0.12$ \\
\hline Annual GHG cost & $\$ 3.67$ & $\$ 1.59$ & $\$ 2.12$ & $\$ 3.41$ \\
\hline
\end{tabular}

\subsection{In-Service Period Assumptions}

Unlike HPS and induction lamps, LEDs tend to dim over time rather than burning out. The IESNA created the LM-80 test standards to measure lumen maintenance for LED light sources (the LEDs, not the luminaires). Lumen maintenance is defined as "the luminous flux remaining output (typically expressed as a percentage of the maximum output) at any selected elapsed operating time."

According to the manufacturers' product specifications, different LED luminaires with varying number of LED units have different $\mathrm{L}_{70}$ lifetimes (expected time to depreciate to $70 \%$ of the original lumen output). Table 5.2 summarizes the rated life of the different LED luminaires under different drive currents.

Table 5.2. Luminaire Life

\begin{tabular}{lllll}
\cline { 2 - 5 } Drive Current & \multicolumn{4}{c}{$\mathrm{L}_{70}$ Life (hours) based on luminaire operating at $15^{\circ} \mathrm{C}\left(59^{\circ} \mathrm{F}\right)$} \\
\cline { 2 - 5 } & $20 \mathrm{LEDs}$ & $30 \mathrm{LEDs}$ & $60 \mathrm{LEDs}$ & $90 \mathrm{LEDs}$ \\
\hline $350 \mathrm{~mA}$ & 185,000 & 171,000 & 151,000 & 147,000 \\
$525 \mathrm{~mA}$ & 117,000 & 106,000 & 89,000 & 80,000 \\
$700 \mathrm{~mA}$ & 81,000 & 70,000 & 55,000 & N/A \\
\hline
\end{tabular}

Source: BetaLED LEDway product specification sheet.

For this demonstration, the LED luminaires used a drive current of $525 \mathrm{~mA}$. Therefore, based on the annual operating hours of 4,100, the $\mathrm{L}_{70}$ lifetimes are around 28 years for the 20-LED luminaire, 26 years for the 30-LED luminaire, 22 years for the 60-LED luminaire, and 20 years for the 90 -LED luminaire.

However, the analysis used a maximum effective life of 15 years for all LED luminaires because much uncertainty still is associated with their rated life based on extrapolated laboratory results. It is also

\footnotetext{
${ }^{1}$ IESNA LM-80-08 IES Approved Method for Measuring Lumen Maintenance of LED Light Sources
} 
likely that current LED technology will be obsolescent 15 years from now, if not sooner, so that a maximum 15-year life assumption appears justified.

For induction lamps, lumen maintenance at 100,000 hours is rated between $55 \%$ and $65 \%$, and around $70 \%$ at 60,000 hours. For this analysis, the useful life of induction lamps is assumed to be 70,000 hours. No salvage value is assumed at the end of the useful life for HPS, induction, or LED luminaires. ${ }^{2}$

Table 5.3. Summary of Base Case Inputs

\begin{tabular}{lllll}
\hline Baseline technology: 70-W HPS & 70 -W HPS & 20 LEDs & 30 LEDs & Induction \\
\hline Expected lifespan & 25 years & 15 years & 15 years & 17 years \\
Initial cost of replacement luminaire & N/A & $\$ 350$ & $\$ 420$ & $\$ 459$ \\
Annual system energy usage & $398 \mathrm{kWh}$ & $172 \mathrm{kWh}$ & $230 \mathrm{kWh}$ & $369 \mathrm{kWh}$ \\
$\begin{array}{l}\text { \% reduction in energy usage compared to HPS } \\
\text { Annual maintenance and replacement costs }\end{array}$ & $\mathrm{N} / \mathrm{A}$ & $57 \%$ & $42 \%$ & $7 \%$ \\
$\begin{array}{l}\% \text { reduction in maintenance and replacement costs } \\
\text { compared to HPS }\end{array}$ & N/A & $42 \%$ & $42 \%$ & $42 \%$ \\
\hline
\end{tabular}

\subsection{Base Case Results}

The base case results are summarized in Table 5.4. Net present value is calculated using a discount rate of $4.5 \%$. A $2 \%$ nominal annual escalation factor is used for labor, materials, and energy cost, which is approximately equal to current long-term inflation forecasts. ${ }^{3}$ For the Retrofit scenario, there is no initial investment for HPS luminaires. The New Construction scenario includes the cost of new HPS luminaires and installation.

Table 5.4. Net Present Value of Systems

\begin{tabular}{lcccc}
\cline { 2 - 5 } & \multicolumn{2}{c}{ Retrofit } & \multicolumn{2}{c}{ New Construction } \\
\cline { 2 - 5 } & $\begin{array}{c}\text { Simple Payback } \\
\text { (years) }\end{array}$ & $\begin{array}{c}\text { Net Present } \\
\text { Value }\end{array}$ & $\begin{array}{c}\text { Simple Payback } \\
\text { (years) }\end{array}$ & $\begin{array}{c}\text { Net Present } \\
\text { Value }\end{array}$ \\
\hline 20 LEDs & 9 & $\$ 122$ & 7 & $\$ 201$ \\
30 LEDs & 12 & $-\$ 15$ & 10 & $\$ 64$ \\
Induction & $17+$ & $-\$ 173$ & 16 & $-\$ 105$ \\
\hline
\end{tabular}

\footnotetext{
${ }^{2}$ This may also prove conservative, given the amount of aluminum in current LED heat sinks, which may at least prevent landfill disposal costs that conventional products could entail. (No disposal costs are currently assumed for any luminaire type.)

${ }^{3}$ For example, the EIA Annual Energy Outlook 2009 uses an annual consumer price inflation rate of $2.1 \%$ in the reference case (p. 2) http://www.eia.doe.gov/oiaf/aeo/pdf/trend_1.pdf. In addition, for internal planning purposes, City of Palo Alto Utilities assumes an annual escalation rate for energy cost at 2\% for the next 15 years; this is based on the mix of electricity sources and contracts in place.
} 
If GHG cost is excluded, then the NPV of replacing HPS with LED luminaires is lowered by around $\$ 20$, and that of replacing HPS with induction, by around $\$ 5$. The simple payback period remains virtually the same. As stated earlier, Palo Alto is part of the Climate Protection Plan and is striving to reduce GHG by $15 \%$ of 2005 levels. Based on this analysis, the monetization of GHG really does not affect the payback period. Therefore, Palo Alto will have to consider steps that reduce GHG (e.g., reducing the energy used by the streetlights) without the benefit of GHG costs helping the economic case.

\subsection{Sensitivity Analysis}

The analysis also investigated the sensitivity of the NPV to uncertainties in a number of variables, including the life of the LED luminaire, reduction in maintenance cost, and initial LED luminaire cost. For the sensitivity analysis, only the 70- HPS retrofit scenario was examined, and that required recalculation of the NPV by changing the uncertainty variable from the base case value by $-20 \%,-10 \%$, $+10 \%$, and $+20 \%$.

\subsubsection{Sensitivity Analysis on the In-Service Period of LEDs}

The base case assumes an in-service period for the LEDs of 15 years, with 4,100 hours of operation per year. A typical warranty for LED luminaires by this manufacturer runs between 5 to 10 years. The actual in-service period could be less or more than 15 years, however.

A sensitivity analysis on the effect of the in-service period to the economic results (Table 5.5) shows that as the period of the 20-LED luminaire increases by $20 \%$ to 18 years, the NPV increases from $\$ 122$ to $\$ 217$. This result indicates that estimates of cost-effectiveness are fairly sensitive to the assumed lifetime, due to the impact that assumption has on the number of years the investment is generating returns in the form of energy and maintenance savings.

Table 5.5. Results of the Sensitivity Analysis on the In-Service Period of LEDs

\begin{tabular}{|c|c|c|c|c|c|}
\hline \multicolumn{6}{|c|}{ Base case: In-service period of LED luminaires $=15$ years } \\
\hline & $-20 \%$ & $-10 \%$ & $0 \%$ & $+10 \%$ & $+20 \%$ \\
\hline 20-LED Luminaire & $\$ 21$ & $\$ 55$ & $\$ 122$ & $\$ 155$ & $\$ 217$ \\
\hline 30-LED Luminaire & $-\$ 105$ & $-\$ 74$ & $-\$ 15$ & $\$ 14$ & $\$ 69$ \\
\hline
\end{tabular}

\subsubsection{Sensitivity Analysis on the Luminaire Cost of LEDs}

The price of LED luminaires has been declining steadily over the last several years. ${ }^{4}$ Pricing continues to vary significantly, however, often even among products from the same manufacturer due to different color temperatures, product lines, or other differences. A sensitivity analysis on the luminaire cost shows that as cost of this 20-LED luminaire decreases by $20 \%$ to $\$ 280$, the NPV increases from $\$ 122$ to $\$ 195$ (Table 5.6).

\footnotetext{
${ }^{4}$ For example, the City of Oakland conducted two demonstration projects with LED streetlights and found that over a single 12 month period between the two projects, the luminaire cost decreased $34 \%$. See http://www1.eere.energy.gov/buildings/ssl/gatewaydemos_results.html.
} 
Table 5.6. Results of the Sensitivity Analysis on the Luminaire Cost

\begin{tabular}{lccccc}
\hline Base case: 20 -LED luminaire cost $=\$ 350 ; 30-$ LED luminaire cost $=\$ 420$ \\
\hline & $-20 \%$ & $-10 \%$ & $0 \%$ & $+10 \%$ & $+20 \%$ \\
\cline { 2 - 6 } 20-LED Luminaire & $\$ 195$ & $\$ 159$ & $\$ 122$ & $\$ 86$ & $\$ 49$ \\
30-LED Luminaire & $\$ 73$ & $\$ 29$ & $-\$ 15$ & $-\$ 59$ & $-\$ 103$ \\
\hline
\end{tabular}

\subsubsection{Sensitivity Analysis on the Initial Efficacy of LEDs}

In the base case, the analysis uses the metered power draw for the LED luminaires to determine the NPV of converting a 70-W HPS to a 20-LED or 30-LED luminaire. The metered values are $42 \mathrm{~W}$ for the 20-LED luminaire and $56 \mathrm{~W}$ for the 30-LED luminaire. As LED technology continues to improve, the efficacy of LED luminaires is expected to increase, meaning that lower-wattage luminaires will be needed to supply a given illumination. A sensitivity analysis on the system wattage under a 70-W HPS retrofit scenario of LEDs gives the following results: as the system power draw for the 20-LED luminaire decreases by $20 \%$ to $33.6 \mathrm{~W}$, the NPV increases from $\$ 122$ to $\$ 160$ (Table 5.7).

Table 5.7. Results of the Sensitivity Analysis on the Initial Efficacy of LEDs

\begin{tabular}{|c|c|c|c|c|c|}
\hline \multicolumn{6}{|c|}{$\begin{array}{l}\text { Base case: System watts for } 20 \text {-LED luminaire }=42 \mathrm{~W} \text {; } \\
\text { system watts for } 30 \text {-LED luminaire }=56 \mathrm{~W}\end{array}$} \\
\hline & $-20 \%$ & $-10 \%$ & $0 \%$ & $+10 \%$ & $+20 \%$ \\
\hline 20 LEDs & $\$ 160$ & $\$ 141$ & $\$ 122$ & $\$ 103$ & $\$ 84$ \\
\hline 30 LEDs & $\$ 36$ & $\$ 11$ & $-\$ 15$ & $-\$ 40$ & $-\$ 66$ \\
\hline
\end{tabular}

\subsubsection{Sensitivity Analysis on the Maintenance Cost of LEDs}

For the base case, the analysis assumes that LED or induction luminaires will reduce maintenance cost by $30 \%$, attributed to the reduced hours to replace HPS lamps (i.e., \$39/luminaire for LED versus \$56/luminaire for HPS.) The actual maintenance costs of LED and induction luminaires may, however, deviate from this estimate. A sensitivity analysis on the annual maintenance cost for the 20-LED luminaire shows that decreasing it by $20 \%$ to $\$ 31.2$ increases the NPV from $\$ 122$ to $\$ 217$.

Table 5.8. Results of the Sensitivity Analysis on the Maintenance Cost of LEDs

\begin{tabular}{llllll}
\hline Assumption: & Annual maintenance cost for 20 & LEDs and 30 LEDs $=\$ 39 /$ luminaire & \\
\hline & $-20 \%$ & $-10 \%$ & $0 \%$ & $+10 \%$ & $+20 \%$ \\
20 LEDs & $\$ 217$ & $\$ 170$ & $\$ 122$ & $\$ 75$ & $\$ 27$ \\
30 LEDs & $\$ 80$ & $\$ 33$ & $-\$ 15$ & $-\$ 62$ & $-\$ 110$ \\
\hline
\end{tabular}

1. Figures 5.1 and 5.2 plot the NPV against the uncertainty variables with values ranging from $20 \%$ to $+20 \%$. Based on the plots, the uncertainty variables are ranked according to their 
impact on the NPV (from the highest impact to the least impact) as follows: maintenance cost, in-service period, luminaire cost, and luminaire efficacy.

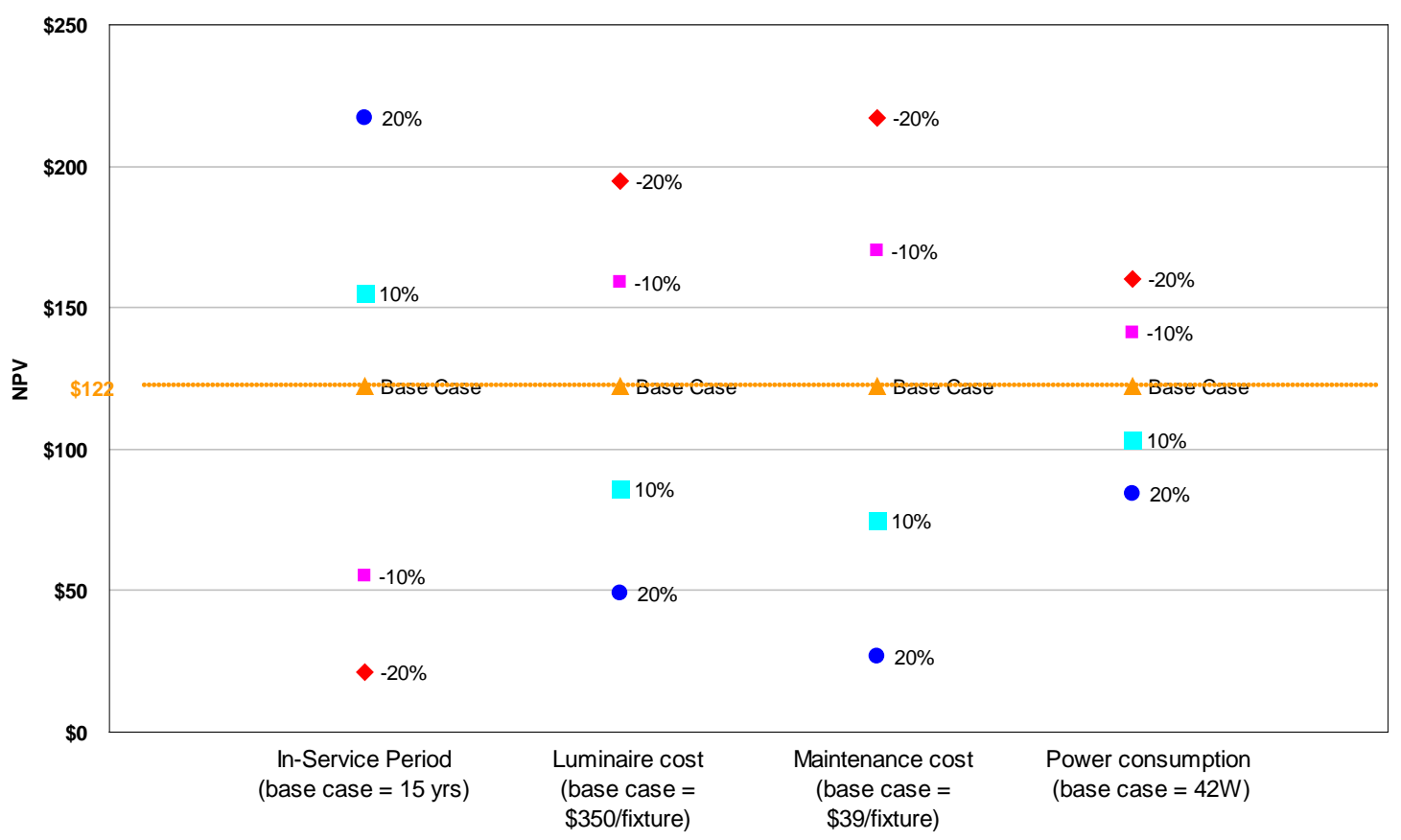

Figure 5-1. Sensitivity Analysis on the Net Present Value of 20-LED Luminaires Replacing 70-W HPS

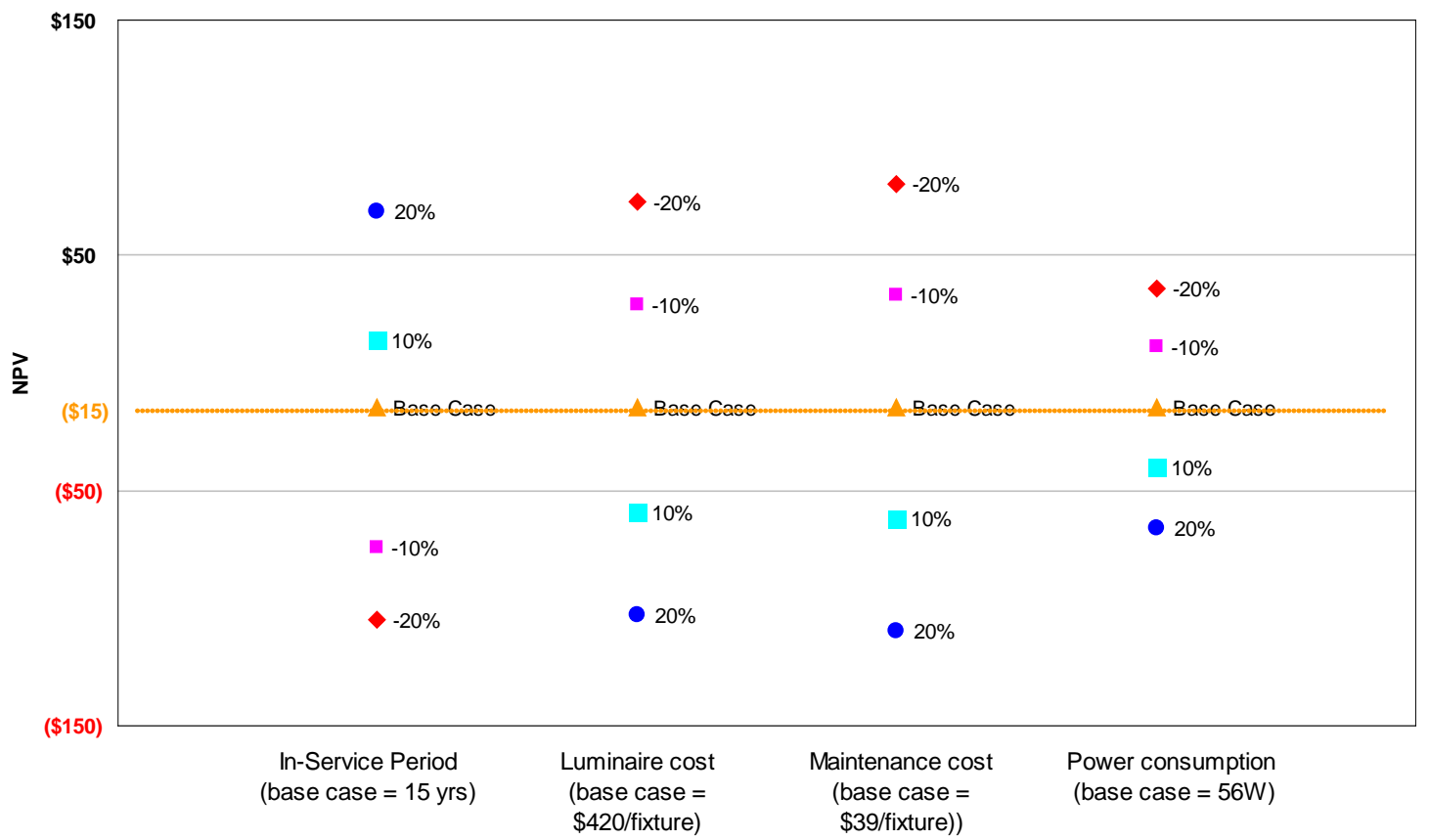

Figure 5-2. Sensitivity Analysis on the Net Present Value of 30-LED Luminaires Replacing 70-W HPS 


\subsection{Economics for Replacing Different HPS Wattage with LED Luminaires}

Palo Alto employs HPS lamps with different wattages throughout the city. Residential areas typically use $70-\mathrm{W}$ and 100-W (nominal) lamps, while commercial and high-traffic areas have 150-W and 250-W (nominal) lamps in the luminaires. Therefore, the economic analysis also looked at the simple payback and NPV for replacing 70-W, 100-W, 150-W, and 250-W HPS luminaires with LED luminaires. Table 5.9 summarizes the results using the base case assumptions for operating period and maintenance cost reductions.

Table 5.9. Net Present Value of Different LED Systems Replacing Different-Wattage HPS Systems

\begin{tabular}{lcccc}
\hline & \multicolumn{2}{c}{ Retrofit } & \multicolumn{2}{c}{ New Construction } \\
\cline { 2 - 5 } & $\begin{array}{c}\text { Simple Payback } \\
\text { (years) }\end{array}$ & $\begin{array}{c}\text { Net Present } \\
\text { Value }\end{array}$ & $\begin{array}{c}\text { Simple Payback } \\
\text { (years) }\end{array}$ & $\begin{array}{c}\text { Net Present } \\
\text { Value }\end{array}$ \\
\hline $\begin{array}{l}\text { 20 LEDs replacing } \\
70 \text {-W HPS }\end{array}$ & 9 & $\$ 127$ & 7 & $\$ 205$ \\
$\begin{array}{l}\text { 30 LEDs replacing } \\
70 \text {-W HPS }\end{array}$ & 12 & $-\$ 15$ & 10 & $\$ 64$ \\
$\begin{array}{l}\text { 40 LEDs replacing } \\
\text { 100-W HPS }\end{array}$ & 10 & $\$ 90$ & 7 & $\$ 216$ \\
$\begin{array}{l}\text { 60 LEDs replacing } \\
\text { 150-W HPS } \\
\text { 90 LEDs replacing }\end{array}$ & 12 & $-\$ 63$ & 10 & $\$ 99$ \\
250-W HPS & 13 & $-\$ 157$ & 11 & $\$ 16$ \\
\hline
\end{tabular}

Given that Palo Alto has a total number of around 6,300 HPS luminaires, the projected payback for replacing all existing HPS luminaires is 11 years, with an NPV of $\$ 330,000$. The initial investment for retrofitting all HPS luminaires with LED luminaires including installation cost is $\$ 4,169,442$. The assumptions for this analysis are given in Table 5.10.

Table 5.10. Assumptions Underlying Installation and Payback Costs for Retrofitting HPS Luminaires with LED Luminaires

\begin{tabular}{lllll}
\hline HPS rated lamp power (watts) & 70 & 100 & 150 & 250 \\
\hline Number of luminaires & 2847 & 1975 & 371 & 1106 \\
\hline HPS input power (watts) & 97 & 130 & 185 & 295 \\
\hline Replacement LED luminaire type & 20 -LED & 40 -LED & 60 -LED & 90 -LED \\
\hline Replacement LED luminaire unit cost before tax & $\$ 350$ & $\$ 465$ & $\$ 650$ & $\$ 980$ \\
\hline Installation cost per unit & $\$ 100$ & $\$ 100$ & $\$ 100$ & $\$ 100$ \\
\hline LED input power (watts) & 42 & 70 & 109 & 168 \\
\hline Power reduction & $57 \%$ & $46 \%$ & $41 \%$ & $43 \%$ \\
\hline LED useful life (hours) & 61,500 & 61,500 & 61,500 & 61,500 \\
\hline
\end{tabular}




\subsection{Economics for Remote Monitoring and Dimming Control}

The demonstration also tested the use of remote monitoring and dimming control with LED and induction streetlight luminaires. The remote dimming control system was deployed in downtown Palo Alto with LED and induction luminaires replacing 150-W HPS luminaires. Cost components to the remote monitoring system include Echelon's i.LON segment controller $(\$ 2,000)$, the modem and router that work with the segment controller and communicate to individual luminaires over the power line (\$500), installation of the segment controller on a streetlight pole (\$100), and the i.Lon chip that is preinstalled with each luminaire (\$75). Assuming 10 streetlight luminaires per circuit and that one segment controller is needed for each circuit, the estimated incremental cost per luminaire for the remote monitoring and dimming control is $\$ 335$. This same incremental cost would apply to any replacement luminaire, regardless of the wattage of the existing HPS luminaire.

Based on $25 \%$ dimming for 5 hours per day, the simple paybacks and net present values under the remote monitoring scenario are as summarized in Table 5.11.

Table 5.11. Economic Analysis of Dimming Control for LED or Induction

\begin{tabular}{lcccc}
\hline \multirow{2}{*}{$\begin{array}{c}\text { Retrofit scenario: } \\
\text { replacing 150-W } \\
\text { HPS) }\end{array}$} & \multicolumn{2}{c}{ Without Dimming } & \multicolumn{2}{c}{ With Dimming } \\
\cline { 2 - 5 } & $\begin{array}{c}\text { Simple Payback } \\
\text { (years) }\end{array}$ & $\begin{array}{c}\text { Net Present } \\
\text { Value }\end{array}$ & $\begin{array}{c}\text { Simple Payback } \\
\text { (years) }\end{array}$ & $\begin{array}{c}\text { Net Present } \\
\text { Value }\end{array}$ \\
\hline 60 LEDs & 12 & $-\$ 63$ & $15+$ & $-\$ 358$ \\
$165-W$ induction & 15 & $-\$ 145$ & $17+$ & $-\$ 199$ \\
\hline
\end{tabular}

The deployment of the remote monitoring system is currently not economical, based on the additional system costs. In addition, Palo Alto staff has other concerns related to the deployment of a dimming system, including the unknown failure rates of the electronic components and potential complaints about the lower illumination level when the luminaires are dimmed. 


\subsection{Discussion}

\subsection{Illuminance}

The analysis of three sites and four different luminaires in this demonstration produced some significant findings regarding illuminance:

- Measured values can vary greatly. It is worth noting that the three different sets of points measured used the same HPS luminaire with approximately the same spacing, yet the averages for the three sets of measurements ranged from 0.27 to $0.44 \mathrm{fc}$. These values differed somewhat (two lower, one higher) from the computer-calculated average illuminance. Computer models cannot accurately take into account all realities like tree canopies and manufacturing tolerances.

- Palo Alto does not currently have illuminance criteria for its streets. However, if the three sets of HPS illuminance data taken are averaged, the result is $0.37 \mathrm{fc}$. This value rounded to the nearest single significant digit is $0.4 \mathrm{fc}$, which is consistent with RP-8-00 for local roads having low pedestrian conflicts. Therefore, Palo Alto could consider adopting RP-8-00 as the city moves forward.

- None of the measured lighting systems produced results compliant with RP-8-00 in terms of uniformity (which requires 6:1 avg/min). Shadowing from both tree canopies and cars, along with pole spacing, are probably responsible for the most part. The City could mitigate the tree shadowing effects by either pruning the trees or by lowering the luminaires below the canopy.

\subsection{Economics}

The analysis demonstrates that converting existing streetlights in Palo Alto from HPS to LED would not be economically favorable by most measures, with simple paybacks ranging between 9 and 13 years, depending on the wattage of the HPS luminaire being replaced. Using a relatively low discount rate of $4.5 \%$ among other conservative assumptions, most options offered a negative net present value. Under a new construction scenario, the corresponding paybacks are slightly shorter, ranging from 7 to 10 years, with a longer payback for the higher-wattage replacements. For the city of Palo Alto overall, replacing the existing 6,300 HPS luminaires with LED luminaires would have a projected payback of 11 years.

A comparison of the cost-effectiveness of replacing different wattages of HPS with LED luminaires demonstrates that the lower-wattage LED products are more cost-effective than the higher-wattage versions. This is explained by the fact that a close correlation exists between the required output of an LED product and its cost, due to a general requirement for an increased number of LEDs, more heat sink material, a physically larger luminaire to house the additional components, and other factors. This correlation between output and cost exists to a much smaller degree with conventional products; hence, LEDs tend to become less cost-competitive as their required output increases. Additionally, the relative significance of losses in magnetic HPS ballasts decreases as the lamp rated power increases. For example, the ballast for the 70 -W lamp draws $96 \mathrm{~W}$ (ballast loss $27 \%$ of input power), the ballast for the 150 -W lamp draws $185 \mathrm{~W}$ (ballast loss $19 \%$ of input power), and the ballast for the $250-\mathrm{W}$ lamp draws $295 \mathrm{~W}$ (ballast loss 15\% of input power). Therefore, under the retrofit scenario, the payback increases from 9 to 13 years as the HPS wattage increases from $70 \mathrm{~W}$ to $250 \mathrm{~W}$. 
In this case, the economics of replacing HPS luminaires with induction luminaires is less favorable than with LEDs. The cost of the induction luminaire used to replace a 70-W HPS is higher than the cost of a 30-LED luminaire and achieves only $6 \%$ energy savings compared to the $44 \%$ energy savings of the LED. In the base case of replacing a 70-W HPS luminaire with an induction luminaire, the payback periods under the retrofit and new construction scenarios are $17+$ and 15 years, respectively.

The analysis also shows that it is currently uneconomical to integrate a remote monitoring and dimming control system with LED or induction streetlights into the Palo Alto system. The incremental cost per streetlight luminaire for remote monitoring is $\$ 335$. This is based on the current communication technology for the segment controller to communicate to individual luminaires, which requires one segment controller for every circuit. Assuming a dimming schedule of 5 hours per day with $25 \%$ less energy usage, the deployment of such a system increases the payback for a 60-LED luminaire from 12 to $15+$ years. Although deploying a remote dimming system might make sense for HPS and other higherwattage streetlights, the incremental energy savings from dimming low-wattage LED lights are insufficient to justify the cost.

\subsection{Stakeholder Feedback}

The demonstration project sought to engage the city's residents and other stakeholders to get input on the options to reduce the energy usage of its streetlighting system. Feedback was gathered from three interested parties - the local community, the Palo Alto Police Department, and the city's Utilities Department operations staff who currently maintain the HPS streetlights.

To inform the community of the demonstration project, a notification letter with an enclosed survey form was sent to approximately 200 residents living near the test sites along Amarillo Avenue and Colorado Avenue. A news page was created in the City of Palo Alto's website for the streetlight demonstration (www.cityofpaloalto.org/streetlightpilot) with a link to an online feedback form. Signs were posted on the poles of each test streetlight luminaire to indicate the type of streetlight technology deployed and to direct the viewer to the online news page for additional information and feedback. Additionally, the city and Palo Alto Neighborhoods (PAN) jointly hosted an evening walk-through tour to solicit in-person feedback from residents.

The informal survey questionnaire reported the types and characteristics of alternative streetlighting technologies being tested as a replacement to the HPS streetlights. The results of the survey, therefore, may be biased due to the information presented to survey respondents; for example, energy efficiency and/or mercury content of the different lighting technologies, or projected maintenance savings of the alternatives. However, it is still useful to report some of the results specifically pertaining to perceived quality of the various light sources.

Overall, respondents subjectively preferred the 30-LED streetlights over the other lighting choices. The 20-LED and HPS streetlights were tied in a close second, and induction was the least preferred technology. Increased color perception and visibility were given as key advantages of LED luminaires. There were some negative comments related to LED luminaires, including excessive glare and the color (6000K) of the LED light output, which was perceived as "too cold" and "harsh" compared to that of induction and HPS light. 
Another stakeholder group, the streetlight maintenance staff within the city's Electric Utilities operations division, expressed concerned about the long-term maintenance of the various systems. This division currently employs a group replacement schedule for the HPS lamps of once every 5 years. However, it is not yet clear what the maintenance procedures will be for LED streetlights, given that LEDs do not burn out but rather gradually reduce output over time. Further, concerns were raised that the in-service periods might be different based on the number of LEDs per luminaire, in which case a replacement schedule for the LED lights might have to account for the locations of different-wattage luminaires.

Of the issues above, probably the only one of real remaining concern is CCT. Since these products were installed, comparable products of lower CCT have become available, and the evaluated 30-LED luminaires have since been replaced by the manufacturer with $4300 \mathrm{~K}$ units.

\subsection{Preferred Luminaire/Light Source}

Based on the combined metrics of subjective satisfaction, illuminance performance, energy savings, and economics, the 30-LED luminaire ranked the highest compared to both the HPS and induction luminaires. The 30-LED luminaire produced the highest average illuminance $(0.43 \mathrm{fc})$ of the systems while saving $44 \%$ of the energy compared to the baseline HPS. The 30-LED system had a payback of 12 years under a retrofit scenario and 10 years under a new construction scenario. Note, however, that prices continue to change rapidly so that these payback periods have likely improved in the short time since the test samples were originally purchased.

\section{Appendix A}

\section{Luminaire Photometric Testing Results}





\section{Appendix A}

\section{Luminaire Photometric Testing Results}

The tables in this appendix provide the measured illuminance values in footcandles (fc) for both products across the measured grid.

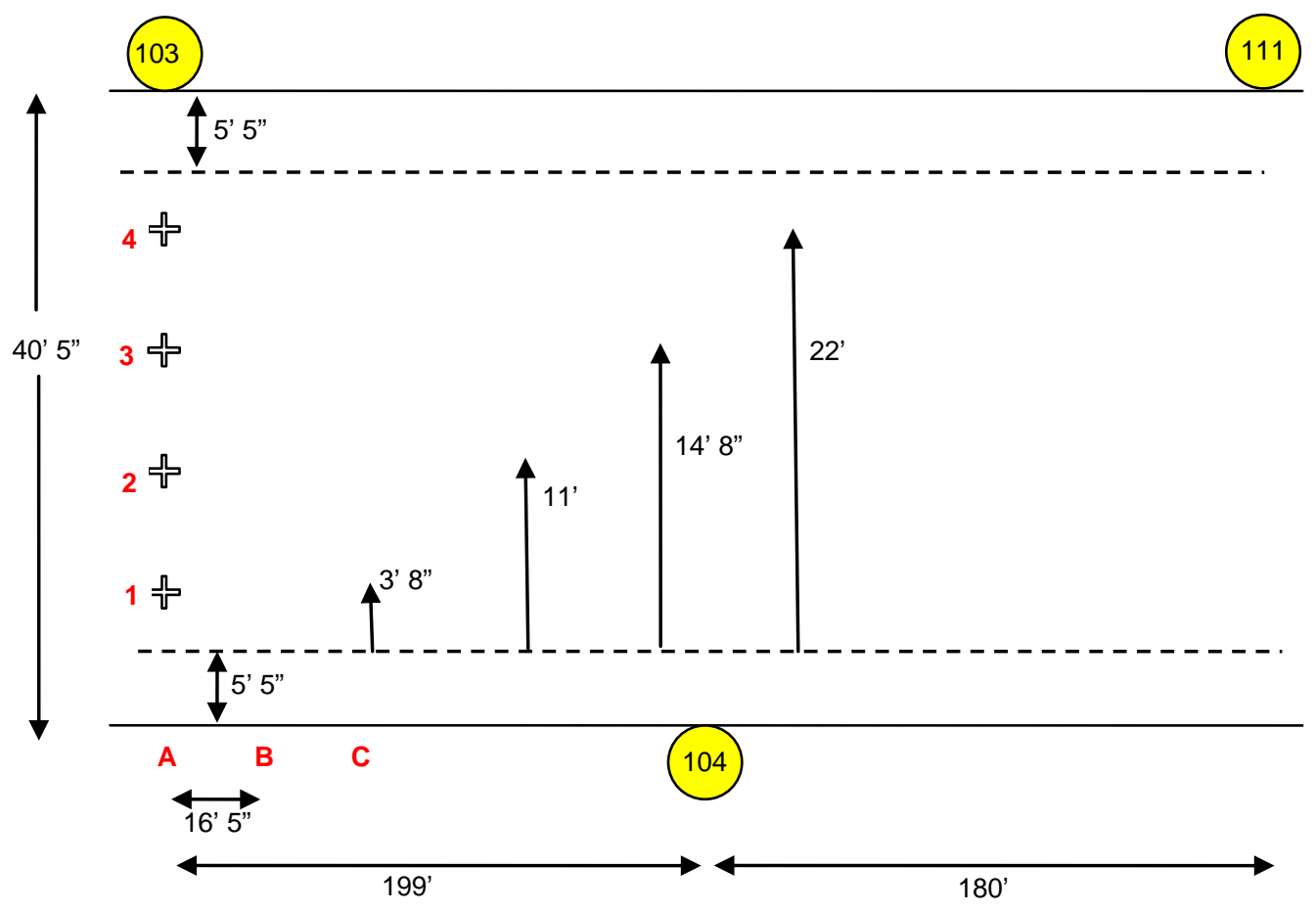

Figure A.1. 20-LED Test Site Colorado 1

TableA.1. Comparison of Colorado Poles 103, 104, and 111

\begin{tabular}{lrrrrrrrr}
\hline & \multicolumn{3}{c}{ High-Pressure Sodium } & \multicolumn{5}{c}{ Light-Emitting Diode } \\
\hline & 1 & 2 & 3 & 4 & 1 & 2 & 3 & 4 \\
\hline A & 0.38 & 0.86 & 1.65 & 1.99 & 0.51 & 0.65 & 0.92 & 0.98 \\
B & 0.39 & 0.71 & 0.88 & 0.45 & 0.21 & 0.4 & 0.39 & 0.39 \\
C & 0.28 & 0.68 & 0.25 & 0.12 & 0.14 & 0.16 & 0.14 & 0.19 \\
D & 0.09 & 0.37 & 0.29 & 0.12 & 0.08 & 0.07 & 0.10 & 0.09 \\
E & 0.21 & 0.14 & 0.07 & 0.12 & 0.10 & 0.09 & 0.07 & 0.09 \\
F & 0.14 & 0.08 & 0.06 & 0.2 & 0.05 & 0.06 & 0.03 & 0.03 \\
G & 0.07 & 0.13 & 0.08 & 0.08 & 0.02 & 0.03 & 0.02 & 0.03 \\
H & 0.06 & 0.12 & 0.14 & 0.08 & 0.03 & 0.03 & 0.04 & 0.04
\end{tabular}




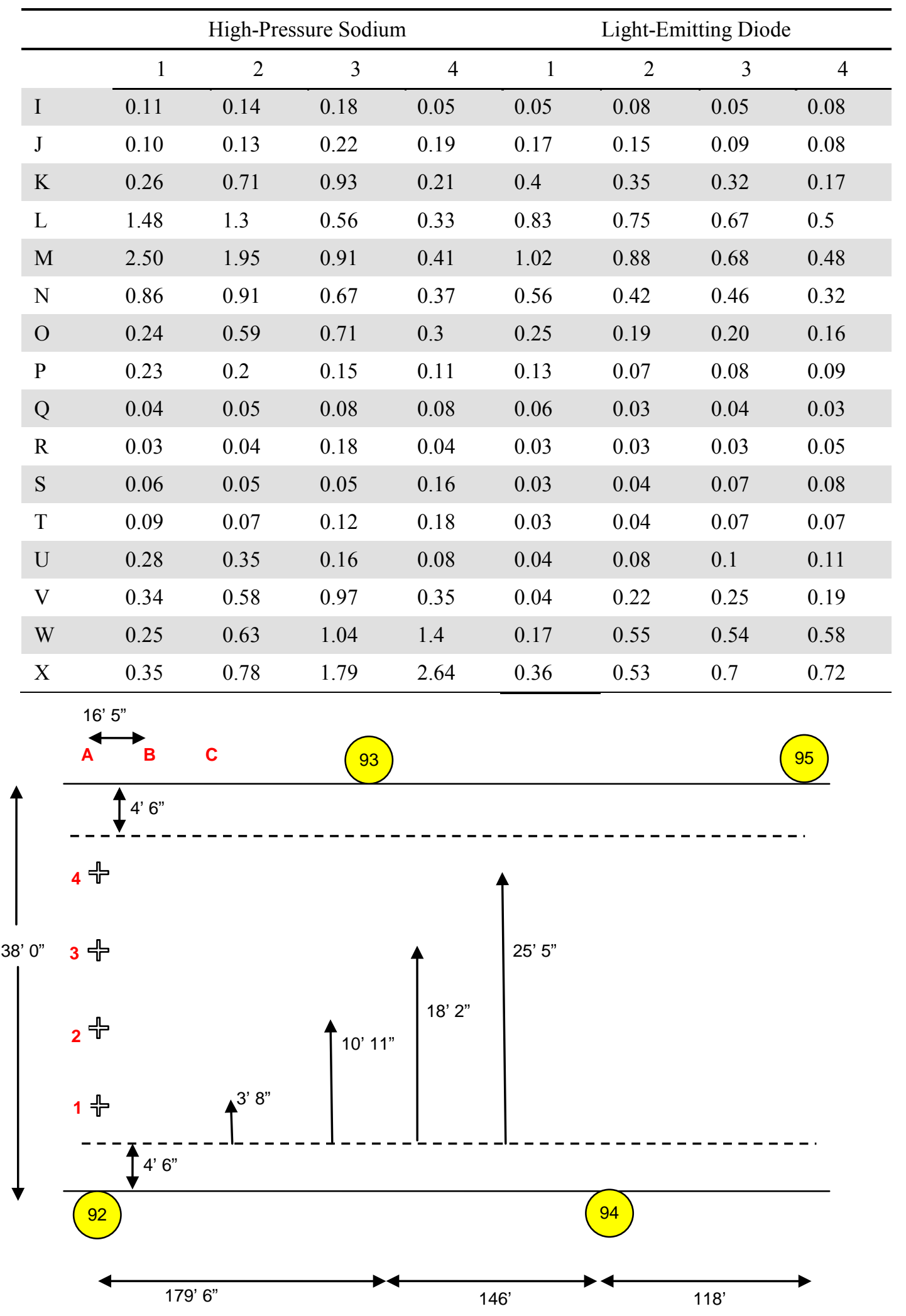

Figure A-2 30-LED Test Site Colorado 2 
TableA.2. Comparison of Colorado Poles 92, 93, 94, and 95

\begin{tabular}{|c|c|c|c|c|c|c|c|c|}
\hline & \multicolumn{4}{|c|}{ High-Pressure Sodium } & \multicolumn{4}{|c|}{ Light-Emitting Diode } \\
\hline & 1 & 2 & 3 & 4 & 1 & 2 & 3 & 4 \\
\hline A & 0.79 & 0.72 & 0.35 & 0.17 & 1.38 & 1.29 & 1.08 & 0.63 \\
\hline $\mathrm{B}$ & 0.3 & 0.43 & 0.43 & 0.17 & 0.55 & 0.64 & 0.55 & 0.35 \\
\hline $\mathrm{C}$ & 0.1 & 0.23 & 0.4 & 0.22 & 0.26 & 0.23 & 0.22 & 0.15 \\
\hline $\mathrm{D}$ & 0.02 & 0.07 & 0.08 & 0.04 & 0.12 & 0.06 & 0.03 & 0.03 \\
\hline $\mathrm{E}$ & 0.08 & 0.03 & 0.04 & 0.04 & 0.05 & 0.04 & 0.03 & 0.02 \\
\hline $\mathrm{F}$ & 0.08 & 0.08 & 0.09 & 0.09 & 0.03 & 0.03 & 0.02 & 0.01 \\
\hline $\mathrm{G}$ & 0.17 & 0.13 & 0.04 & 0.06 & 0.02 & 0.03 & 0.04 & 0.02 \\
\hline $\mathrm{H}$ & 0.06 & 0.09 & 0.18 & 0.18 & 0.06 & 0.12 & 0.08 & 0.02 \\
\hline I & 0.44 & 0.56 & 0.22 & 0.11 & 0.11 & 0.22 & 0.28 & 0.23 \\
\hline $\mathrm{J}$ & 0.34 & 0.61 & 0.57 & 0.33 & 0.29 & 0.59 & 0.65 & 0.57 \\
\hline $\mathrm{K}$ & 0.27 & 0.62 & 1.08 & 1.19 & 0.58 & 1.06 & 1.29 & 1.43 \\
\hline $\mathrm{L}$ & 0.22 & 0.53 & 1.15 & 1.32 & 0.61 & 1.08 & 1.28 & 1.42 \\
\hline $\mathrm{M}$ & 0.21 & 0.33 & 0.5 & 0.3 & 0.27 & 0.5 & 0.56 & 0.55 \\
\hline $\mathrm{N}$ & 0.13 & 0.13 & 0.18 & 0.15 & 0.12 & 0.17 & 0.2 & 0.24 \\
\hline $\mathrm{O}$ & 0.16 & 0.07 & 0.06 & 0.08 & 0.09 & 0.07 & 0.08 & 0.11 \\
\hline $\mathrm{P}$ & 0.06 & 0.02 & 0.07 & 0.06 & 0.07 & 0.09 & 0.07 & 0.08 \\
\hline Q & 0.17 & 0.11 & 0.25 & 0.19 & 0.15 & 0.13 & 0.14 & 0.08 \\
\hline $\mathrm{R}$ & 0.2 & 0.43 & 0.56 & 0.36 & 0.31 & 0.25 & 0.26 & 0.16 \\
\hline $\mathrm{S}$ & 0.52 & 0.58 & 0.48 & 0.32 & 0.58 & 0.65 & 0.66 & 0.32 \\
\hline $\mathrm{T}$ & 1.57 & 1.3 & 0.72 & 0.41 & 1.47 & 1.34 & 1.12 & 0.64 \\
\hline $\mathrm{U}$ & 1.68 & 1.44 & 0.92 & 0.4 & 1.33 & 1.23 & 1.04 & 0.88 \\
\hline
\end{tabular}




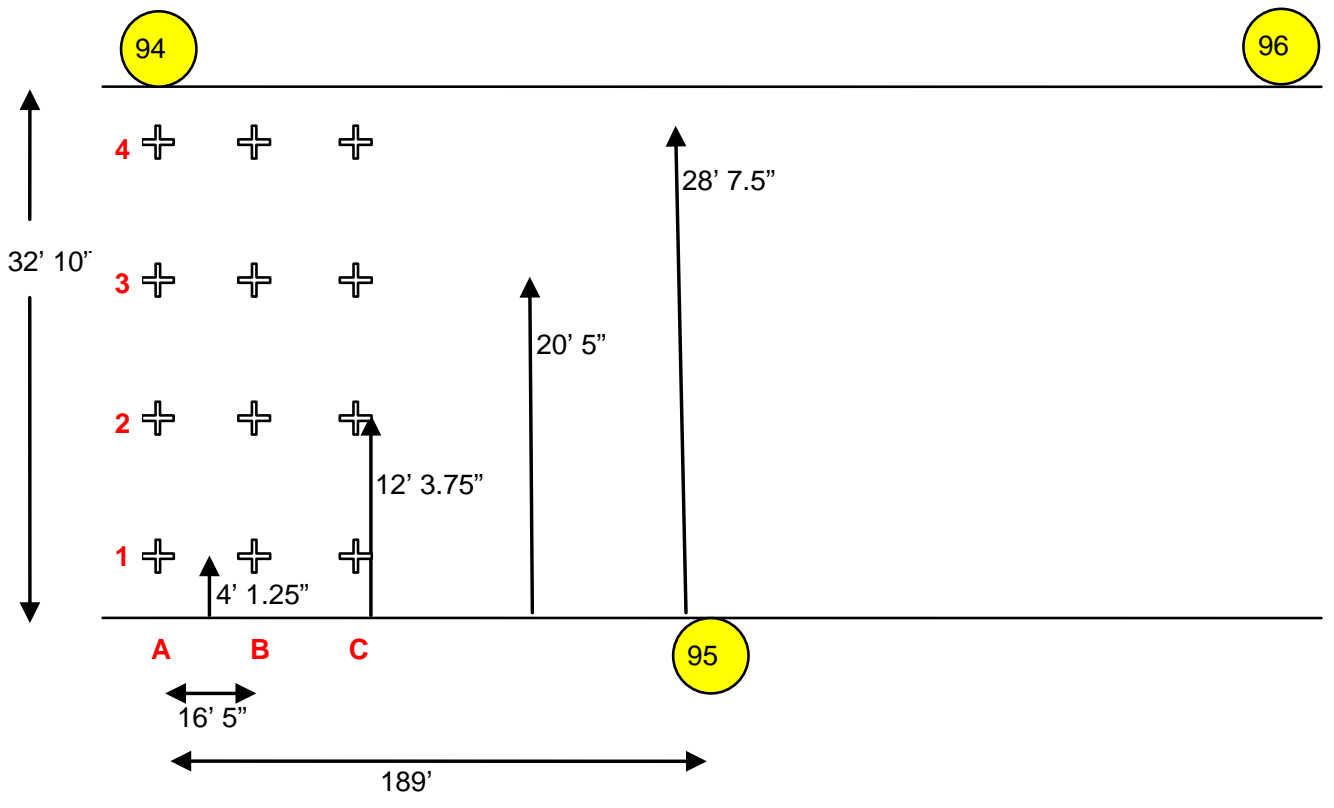

Figure A.3. Induction Test Site Colorado

TableA.3. Comparison of Colorado Poles 94, 95, and 96

\begin{tabular}{|c|c|c|c|c|c|c|c|c|}
\hline & \multicolumn{4}{|c|}{ High-Pressure Sodium } & \multicolumn{4}{|c|}{ Induction } \\
\hline & 1 & 2 & 3 & 4 & 1 & 2 & 3 & 4 \\
\hline A & 0.21 & 0.46 & 1.09 & 1.34 & 0.36 & 0.65 & 1.30 & 1.45 \\
\hline B & 0.13 & 0.34 & 0.80 & 0.01 & 0.19 & 0.35 & 0.46 & 0.21 \\
\hline $\mathrm{C}$ & 0.06 & 0.27 & 0.18 & 0.12 & 0.13 & 0.15 & 0.11 & 0.07 \\
\hline $\mathrm{D}$ & N/A & 0.04 & 0.19 & 0.08 & N/A & 0.22 & 0.09 & 0.05 \\
\hline $\mathrm{E}$ & 0.12 & .018 & 0.17 & 0.20 & 0.11 & 0.02 & 0.04 & 0.03 \\
\hline $\mathrm{F}$ & 0.11 & 0.06 & 0.03 & 0.11 & 0.02 & 0.05 & 0.03 & 0.04 \\
\hline G & 0.26 & 0.35 & 0.35 & 0.35 & 0.02 & 0.04 & 0.03 & 0.05 \\
\hline $\mathrm{H}$ & 0.36 & .011 & 0.26 & N/A & 0.03 & 0.05 & 0.08 & N/A \\
\hline I & N/A & 0.14 & 0.23 & 0.35 & 0.04 & 0.04 & 0.08 & 0.08 \\
\hline $\mathrm{J}$ & 0.09 & 0.012 & 0.20 & 0.18 & 0.11 & 0.15 & 0.24 & 0.22 \\
\hline K & N/A & 0.50 & 0.44 & 0.38 & N/A & 0.75 & 0.62 & 0.38 \\
\hline $\mathrm{L}$ & N/A & 1.01 & 0.57 & 0.19 & N/A & 1.13 & 0.76 & 0.38 \\
\hline M & 0.08 & 0.75 & 0.39 & 0.25 & 0.86 & 0.86 & 0.58 & 0.39 \\
\hline $\mathrm{N}$ & 0.29 & 0.37 & 0.41 & 0.23 & 0.30 & 0.32 & 0.29 & 0.22 \\
\hline $\mathrm{O}$ & 0.14 & 0.14 & 0.42 & N/A & 0.10 & 0.13 & 0.14 & N/A \\
\hline $\mathrm{P}$ & 0.04 & 0.21 & 0.09 & 0.36 & 0.05 & 0.04 & 0.08 & 0.09 \\
\hline Q & 0.06 & 0.05 & 0.14 & 0.17 & 0.03 & 0.02 & 0.03 & 0.03 \\
\hline
\end{tabular}




\begin{tabular}{lccccrrrr}
\hline & \multicolumn{3}{c}{ High-Pressure Sodium } & \multicolumn{5}{c}{ Induction } \\
\hline & 1 & 2 & 3 & 4 & 1 & 2 & 3 & 4 \\
\cline { 2 - 9 } $\mathrm{R}$ & 0.12 & 0.11 & 0.23 & 0.04 & 0.04 & 0.04 & 0.02 & 0.02 \\
$\mathrm{~S}$ & $\mathrm{~N} / \mathrm{A}$ & 0.12 & 0.20 & 0.16 & N/A & 0.01 & 0.03 & 0.04 \\
$\mathrm{~T}$ & $\mathrm{~N} / \mathrm{A}$ & 0.17 & 0.14 & 0.14 & 0.07 & 0.08 & 0.09 & 0.03 \\
$\mathrm{U}$ & 0.33 & 0.20 & 0.13 & 0.16 & 0.09 & 0.09 & 0.09 & 0.04 \\
$\mathrm{~V}$ & 0.44 & 0.83 & 0.18 & 0.19 & 0.16 & 0.22 & 0.06 & 0.03 \\
$\mathrm{~W}$ & 0.21 & 0.33 & 0.15 & 0.15 & 0.33 & 0.43 & 0.08 & 0.13 \\
$\mathrm{X}$ & & & & & 0.40 & 0.78 & 1.5 & N/A \\
\hline
\end{tabular}





\section{Appendix B}

\section{Considerations Regarding Photometry and .IES Files Appendix B}

\section{Considerations Regarding Photometry and .IES Files}

Photometry is used in evaluating luminaires, characterize the distribution of the luminaire, modeling the lighting in a space, and creating three-dimensional renderings and footprints to lay out for spacing.

The data detailing photometric performance for a given luminaire is contained in an .IES file. The IESNA publishes LM-63-02, "IESNA Standard File Format for the Electronic Transfer of Photometric Data and Related Information." Although this document sets the standard for photometric data, it is not foolproof. .IES files can be problematic or modified by anyone because they consist of simple text files containing a string of numbers. As shown in this report, one manufacturer did not actually test its luminaire but rather provided computer-simulated data. Only when investigating the raw text of this file did it become apparent that this file was not actually produced by an independent testing laboratory.

Manipulation of .IES files does not necessarily imply malfeasance and, in fact, may sometimes be appropriate given the cost of testing. For instance, relative photometry is sometimes substituted for absolute photometry to avoid having to test every possible permutation of a modular luminaire. One version of the product is tested via absolute photometry, with instructions provided to users on how the .IES file should be modified to accommodate different available configurations. It may be difficult to determine whether the manufacturer's instructions yield accurate results.

In another example, in using a goniophotometer, testing laboratories charge per angle (both horizontal and vertical) in which a given luminaire is tested. Manufacturers sometimes choose to measure fewer angles to save money. Although some loss of precision may result, this practice is not necessarily done to mislead or exaggerate performance.

In short, this demonstration experienced a range of different circumstances regarding .IES files that were created to LM-63 specifications. However, the mere existence of an .IES file does not guarantee success or accuracy. Specifiers and sites need to request photometry when evaluating a product, but as they request the photometry, the specifier must perform due diligence. Specifiers should ascertain:

- whether he photometry was generated by an independent testing laboratory 
- if tested by the manufacturer, whether the manufacturer is accredited by the National Voluntary Laboratory Accreditation Program (NVLAP)

- if not NVLAP-accredited, whether the laboratory is used in the DOE CALiPER program

- whether the data presented in the file represents absolute or relative photometry.

\section{Appendix C}

\section{LED/Induction Streetlight Pilot Project Notification Letter to Residents}




\title{
Appendix C
}

\section{LED/Induction Streetlight Pilot Project Notification Letter to Residents}

\author{
City of PaloAlto \\ Utilities Department
}

June 30, 2009

\section{LED/INDUCTION STREETLIGHT PILOT PROJECT}

DEAR RESIDENT:

The City of Palo Alto Utilities Department is currently embarking on a pilot project to evaluate altemative streetlighting technologies with the objective of saving energy without compromising current lighting levels. Light Emitting

Divisions

Administration Directoe's Ottiox 60.32027

680. 321.0651 fax

Fublic Relwines

60330256

(6) 321.0651 fax

Customer Support Servios

Ciedomar Sevvioe Center

600302361

606173142 fax

Condz and Collection

6503292333

$65061731426 x$

Velity Marketing Services

6503292341

6506173140 hix

Erginecting

Eloctric

650546400

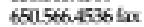

WaterCas Wetewater

6805664500

$600.56645 \%$ fas

Teferommurications

600566456

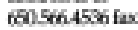

Fesouroe Management

630329269

6005061510 fax

Operationes

Bentric

650966043

650.401802 fiax

WanerCas Wistewater

65040602

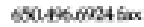

Diode (LED) and induction technologies are designed to use $40 \%$ less energy and last longer than the existing High Pressure Sodium (HPS) streetlights, thereby lowering maintenance costs.

The new streetlights will be installed in three locations along Colorado Avenue and Amarillo Avenue on July 6 to 7,2009 and will stay in place until the end of the year. The attached map shows the locations of these new streetlights. Additionally, there will also be test streetlights installed nearby City Hall along Bryant Street and Ramona Street.

You may experience street activity by City and contractor staff to take lighting measurements in the middle of the night of July $6^{\text {th }}$ and $7^{\text {th }}$. We will be taking utmost care in reducing vehicular noise levels during this measurement period.

Opportunity to provide fcedback

We welcome your feedback on the lighting quality of the new fixtures. A survey form is attached, or go to wrww.cityofpaloalto.org/streetlightpilot. Please complete the survey and return to us in the pre-stamped envelope by July 31, 2009. Your feedback will help the City better design and implement a City-wide rollout of new, more energy efficient streetlighting technologies. For more information about the streetlight pilot project, please contact Christine Tam at 329-2289. (email: christine.tam@cityofpaloalto.org)

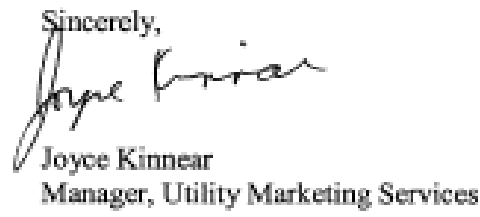

PO. Bax 10850

Palo Alta, CA 94303 


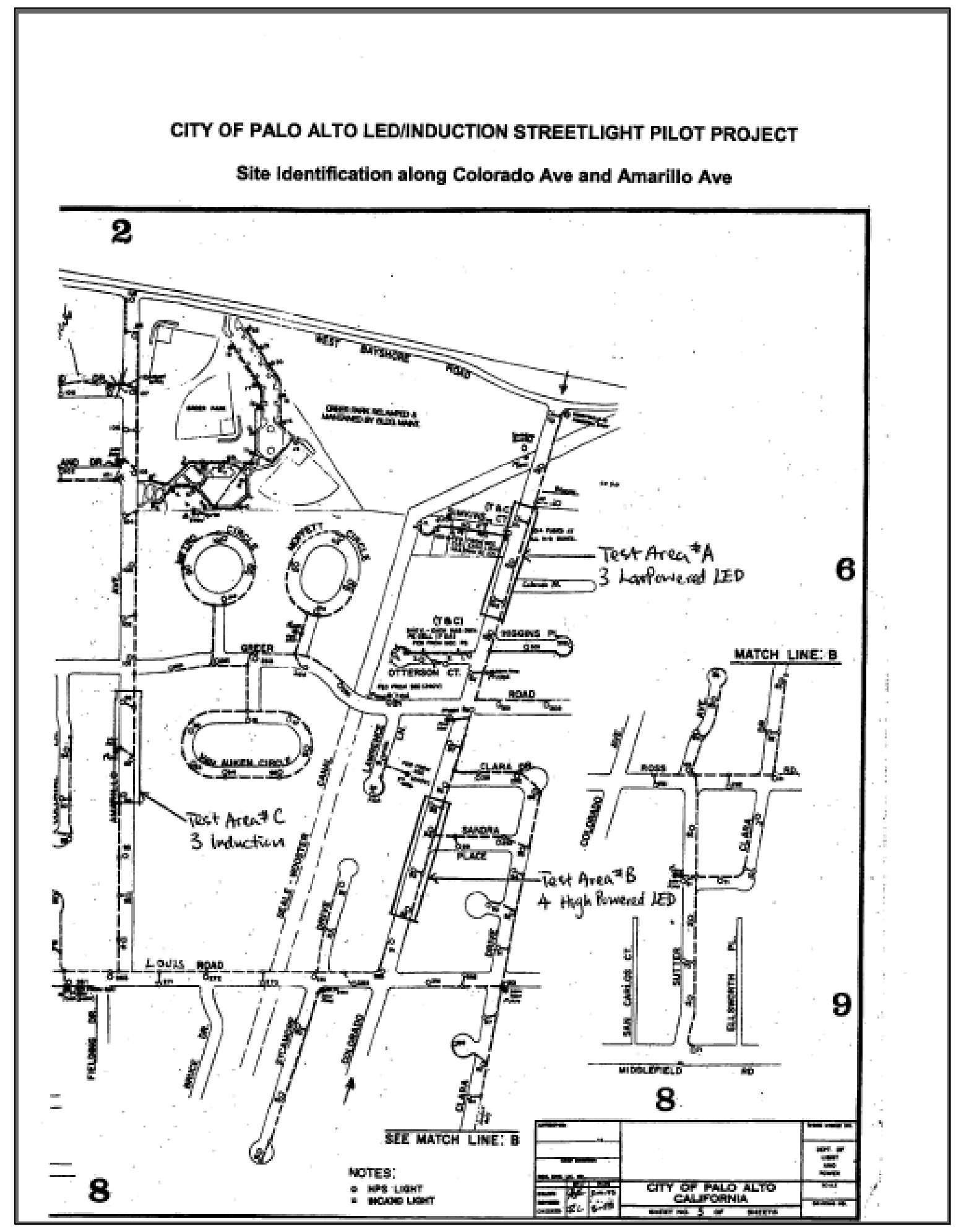




\section{Palo Alto LED/Induction Streetlight Pilot Project Feedback Survey}

For one or more of the following streetlight test areas, please indicate your answers to the questions below. Your responses to each set of fixtures are independent, so there is no need to decide which set you like best. You may, however, provide additional feedback at the end if you have preference for one set over another.

\section{Test Area \#A: 3 low-powered LED lights on Colorado Ave between Simkins Ct and Higgins PI:}

1. Did you notice that the streetlights in Test Area \#A along Colorado Avenue have been replaced? $\square$ Yes $\square$ No

2. How did you experience the new lights?
$\square$ By car
$\square$ By bicycle
$\square$ As a pedestrian
$\square$ From a residence

3. Do you feel that the new street lights have improved your visibility as a pedestrian compared to the older HPS-based adjacent fixtures?
$\square$ Yes
$\square$ No
$\square$ About the same

4. Do you feel that the new street lights have improved your visibility as a driver?
$\square$ Yes
$\square$ No
$\square$ About the same

5. If the new lights are installed along the entire street, it would make the street feel:
Safer?
$\square$ Yes
$\square$ No
About the same
Better ambiance?
$\square$ Yes
$\square$ No
about the same
Too bright?
$\square$ Yes
$\square$ No
$\square$ About the same
Too dim?
$\square$ Yes
$\square$ No
$\square$ About the same
Better color distinction?
DYes
$\square$ No
$\square$ About the same

11. Test Area \#B: 4 high-powered LED lights on Colorado Ave between Clara Dr and Louis Rd:

1. Did you notice that the streetlights in Test Area \#B along Colorado Avenue have been replaced? $\square$ Yes $\square$ No

2. How did you experience the new lights?
$\square$ By car
$\square$ By bicycle
$\square$ As a pedestrian
$\square$ From a residence

3. Do you feel that the new street lights have improved your visibility as a pedestrian compared to the older HPS-based adjacent fixtures?
$\square$ Yes
$\square$ No
About the same

4. Do you feel that the new street lights have improved your visibility as a driver?
$\square$ Yes
$\square$ No
$\square$ About the same

5. If the new lights are installed along the entire street, it would make the street feel:
Safer?
$\square$ Yes
$\square$ No
$\square$ About the same
Better ambiance?
$\square$ Yes
$\square$ No
$\square$ About the same
Too bright?
D Yes
$\square$ No
$\square$ About the same
Too dim?
प Yes
$\square$ No
$\square$ About the same
Better color distinction?
$\square$ Yes
$\square$ No
$\square$ About the same 